\title{
Multiple Effects of Mechanical Stretch on Myogenic Progenitor Cells
}

\author{
Yaqi Wang, ${ }^{1,2, *}$ Jing Song, ${ }^{1,2, *}$ Xinqiang Liu, Jun Liu, ${ }^{1}$ Qiang Zhang, ${ }^{1,2}$ \\ Xiao Yan, ${ }^{1,2}$ Xiao Yuan, ${ }^{1}$ and Dapeng Ren ${ }^{1,2}$
}

Mechanically stretched skeletal muscle undergoes dramatic shifts in structure, mass, and function. In vitro tensile strain models have demonstrated that myogenic progenitor cells, including satellite cells and myoblasts, are highly mechanosensitive cells, and respond to mechanical strain in a wide variety of aspects. However, the experimental results from different researchers and laboratories are not always in support of each other. Moreover, some specific molecules or signaling pathways were reported to play distinct roles in stretched myogenic cells, according to the statements of different studies. The purpose of this review is to integrate the researches conducting in vitro culture of satellite cells or myoblasts and exploring their mechanoresponses using in vitro stretching apparatus. These responses will be categorized into several groups, such as activation, proliferation, myogenic differentiation, cellular damage or apoptosis, properties of plasma membrane, transdifferentiation, reorientation, etc. In addition, detailed experimental designs like culturing conditions and straining regimens will be displayed and compared, to interpret some contradictory statements in different studies. Furthermore, the currently known interconnections among some mechanosensitive pathways will be pictured to give a better understanding about the complex regulations of myogenic cell responses to mechanical stretch. Hopefully, by summarizing the published studies about mechanoresponses of myogenic progenitor cells, future directions, and perspectives would be made clearer to researchers in this field.

Keywords: myogenic stem cells, myoblasts, mechanical stretch, mechanoresponses, cellular signaling

\section{Introduction}

$\mathrm{S}^{\mathrm{k}}$ KELETAL MUSCLE IS A mechanically sensitive tissue, with many aspects (structure, mass, function, etc.) being affected by mechanical forces [1]. During the past decades, intensive in vivo studies have been conducted to investigate the effects of mechanical stimulation on skeletal muscles, using animal models like hindlimb soleus muscle stretching or contraction. Moreover, a substantial number of ex vivo studies, through isolating and stretching single muscle fiber adhering to the flexible culture plates, explored its mechanosensitive properties. Based on these valuable experimental data, it is now generally accepted that mechanical stimuli are an indispensable factor contributing to skeletal muscle homeostasis (see review refs. [2-4]).

Even though numerous researchers reported that these mature muscular structures (myofibers, myofibrils, or even fusing myotubes) are responsive to mechanical stimuli, myogenic resident cells are also inevitably exposed to mechanical forces during daily activity of muscles, giving rise to a new field of research: what part do they play in the stretch-induced physiological and pathological changes of muscles?
Satellite cells are considered the primary stem cells in adult skeletal muscle, locating between the sarcolemma and the basal lamina of the myofiber [5]. Upon external stimuli, they are activated from the quiescent state, and experience both symmetric and asymmetric divisions, guaranteeing the maintenance of the stem cell pool and the production of committed myogenic progenitor cells, also called myoblasts [6]. These myoblasts continue to proliferate, migrate, differentiate, and fuse to form terminally differentiated myotubes, myofibrils, and myofibers. Because of their close location around muscle fibers, it is tempting to assume that both satellite cells and myoblasts are subject to mechanical stretching during physical exercise of skeletal muscle. Thus, stretch-induced behaviors of these cells presumably affect the physiological and pathological changes of skeletal muscle under mechanical stimuli.

Excitingly, with the help of in vitro cell stretching devices, accumulating evidences suggested that satellite cells and myoblasts do react in their unique fashions when they were mechanically deformed during in vitro stretching. Depending on various experimental designs, they were reported to be activated, proliferate, differentiate, or damaged, during stretching stimuli. In addition, stretch also affected

\footnotetext{
${ }^{1}$ Department of Stomatology Medical Center, The Affiliated Hospital of Qingdao University, Qingdao University, Qingdao, China.

${ }^{2}$ Department of Stomatology, Medical School of Qingdao University, Qingdao, China.

*These authors contributed equally to this work, and are first co-authors.
} 
their functions, arrangement, multipotency, etc. In this study, we integrated these in vitro studies and provided an overview of the influences of external mechanical stretching on satellite cells and myoblasts. Furthermore, we speculated the interconnections among different studies exploring the same pathways, and interpreted studies with contradictory results. Finally, future research directions in mechanoresponses of skeletal myoblasts will be addressed.

\section{Stretch-Induced Satellite Cell Activation}

In skeletal muscle, satellite cells are mitotically quiescent under normal condition, but are activated from quiescent state to re-enter cell cycle. In vitro culture of satellite cells has been demonstrated to be activated by mechanical stretch. A relatively clear mechanism has already been proposed regarding stretch-induced satellite cell activation, which will be discussed below.

\section{Hepatocyte growth factor binding to c-mesenchymal-epithelial transition receptor}

Hepatocyte growth factor $(H G F)$ is present in the extracellular matrix (ECM) of uninjured skeletal muscle fibers, and is expressed and secreted by the resident myotubes and satellite cells [7]. So far, $H G F$ is the only growth factor being able to activate quiescent satellite cells when exogenously added in culture medium [8]. Tatsumi et al. [9] first discovered that $H G F$ was released from ECM into medium when satellite cells were stretched. The release of $H G F$ in response to stretch is dependent on $\mathrm{pH}$, with the maximum $H G F$ being released in stretchconditioned medium at $\mathrm{pH} 7.2$ and diminished amounts at $\mathrm{pH}$ 7.0 and 7.4 [10]. Furthermore, stretch-released $H G F$-mediated activation of stretched satellite cells [9]. Interestingly, unlike other tissues, skeletal muscle possesses the active form of $H G F$ that does not require the proteolytic activation of pro- $H G F$ in response to stretch [11].

The specific receptor for $H G F$ in satellite cells is c-mesenchymal-epithelial transition (c-Met) factor, which is present in quiescent satellite cells, thus available for $H G F$ binding [9]. Notably, $H G F$ constantly binds to $c$-Met over a broader $\mathrm{pH}$ range from 6.9 to 7.8 , in contrast to the $\mathrm{pH}-$ sensitive release of $H G F$ mentioned above [10]. By isolating satellite cells from different skeletal muscle tissues, Tatsumi et al. [12] found that satellite cells from lower hind limb muscles displayed the highest activation in response to stretching stimuli, which could be attributed to more $H G F$ release and higher binding sensitivity of $H G F$ to $c$-Met. Although these studies reflected the involvement of c-Met in stretchinduced satellite cell activation, the direct evidence showing this viewpoint is still lacking. Future study employing $c-\operatorname{Met}(-1-)$ satellite cells might fully interpret this point.

\section{Nitric oxide synthase-mediated cleavage of matrix metalloproteinase 2}

Matrix metalloproteinase (MMPs) are a large family of zinc-dependent endopeptidases that catalyze specific ECM constituent. Yamada et al. [13] had confirmed the involvement of $M M P 2$ in stretch-induced rat satellite cell activation, as inhibition of $M M P 2$ by tissue inhibitors of MMPs 1 completely blocked stretch-induced activation. They further demonstrated that $M M P 2$ mediated $H G F$ release in response to stretch [13,14]. To date, $M M P 2,3,7$, and 9 have been found in skeletal muscle [8]. In addition, $M M P 9$ activity and expression were increased in $\mathrm{C} 2 \mathrm{C} 12$ myoblasts during cyclic stretching [15]. Thus, it needs to be clarified whether these $M M P s$ besides $M M P 2$ also participate in mechanical stretchactivated satellite cells.

To catalyze $H G F$ release, proMMP2 $(72 \mathrm{kDa})$ must be converted into active $M M P 2(52 \mathrm{kDa})$, which relies on nitric oxide synthase $(N O S)$-mediated nitric oxide $(N O)$ production in stretched satellite cell culture [14]. Skeletal muscles mainly express neuronal NOS ( $n N O S$ or NOS-I) and some endothelial NOS (NOS-III), but not inducible NOS (NOS-II) [10]. Inhibition of $n N O S$ abrogated proMMP2 conversion, $H G F$ release, and satellite cell activation during mechanical stretching $[14,16]$. Collectively, these studies established the $n N O S-N O-M M P 2-H G F$ axis that mediated stretch-induced activation of satellite cells.

\section{Involvement of calcium/calmodulin}

Hara et al. [17] proposed that mechanosensitive (MS) cation channel and the long-lasting-type voltage-gated calcium ion $(L-V G C)$ channel mediate the influx of extracellular calcium ions in satellite cell cultures in response to stretch. Moreover, they confirmed that stretch-induced calcium influx initiated the $H G F$ release and satellite cell activation through calmodulin pathway [18]. The transient receptor potential canonical channel 1 represents an essential component of MS channel in C2C12 myoblasts [19]. Another potential candidate for MS channel in myoblasts is Na cation pump, which is activated by alpha2 subunit of $\mathrm{Na}-\mathrm{K}$-ATPase that translocated from endosomes to the plasma membrane (PM) in primary rat myoblasts during mechanical strain [20].

Thus, according to the model of Hara et al., the cations streamed into cells through these MS channels, and induced local depolarization of the cell membrane, which promoted gating of adjacent $L-V G C$ channels and allowed sufficient calcium influx [17].

\section{Inhibition of inflammatory autoimmune}

Interestingly, the Calmodulin-nNOS-MMP2-HGF-cMet pathway activated by mechanical stretch in myoblasts not only stimulates their entry into cell cycle, but also concomitantly inhibits the expressions of potential autoantigens. This was demonstrated by the elevated expressions of autoantigens ( $M i$ 2, HRS, DNA-PKcs, U1-70) and toll-like receptor 3 by inhibition of Calmodulin-nNOS-MMP2-HGF-cMet pathway in C2C12 myoblasts under 10\% cyclic radial stretch [21]. Thus, the authors stated that appropriate mechanical stimuli are beneficial in preventing the inflammatory myopathies. This is of particular importance in chronic inflammatory situations, since regenerating muscle cells are considered to be the main source of autoantigens and contribute to the progression of inflammatory myopathies during inappropriate exercise training [21].

\section{Effect of Stretch on Skeletal Myoblast Proliferation}

Up to date, most studies conducting in vitro stretching of myoblast cultures agreed that mechanical stretch is a positive factor in regulating myoblast proliferation. A detailed 


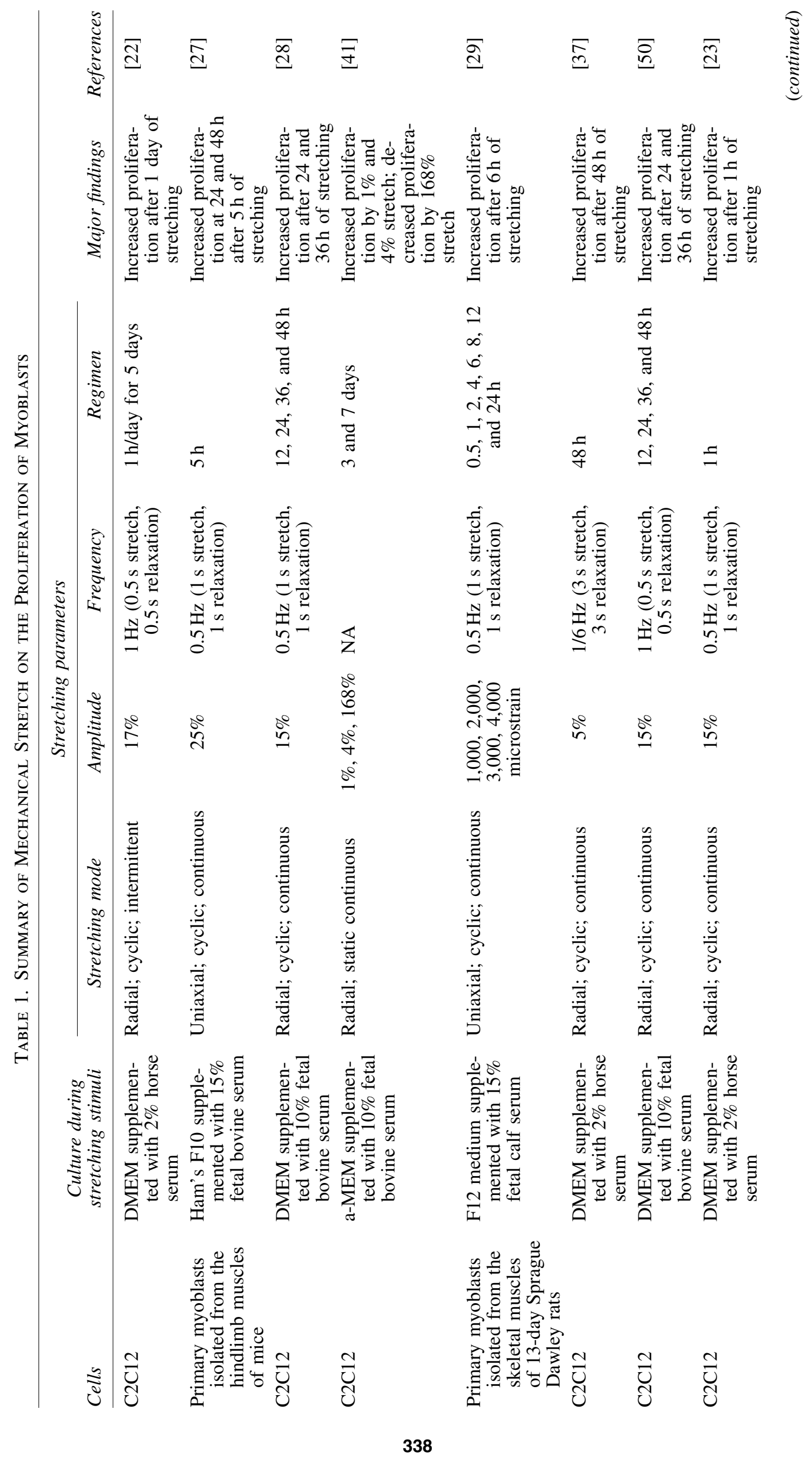




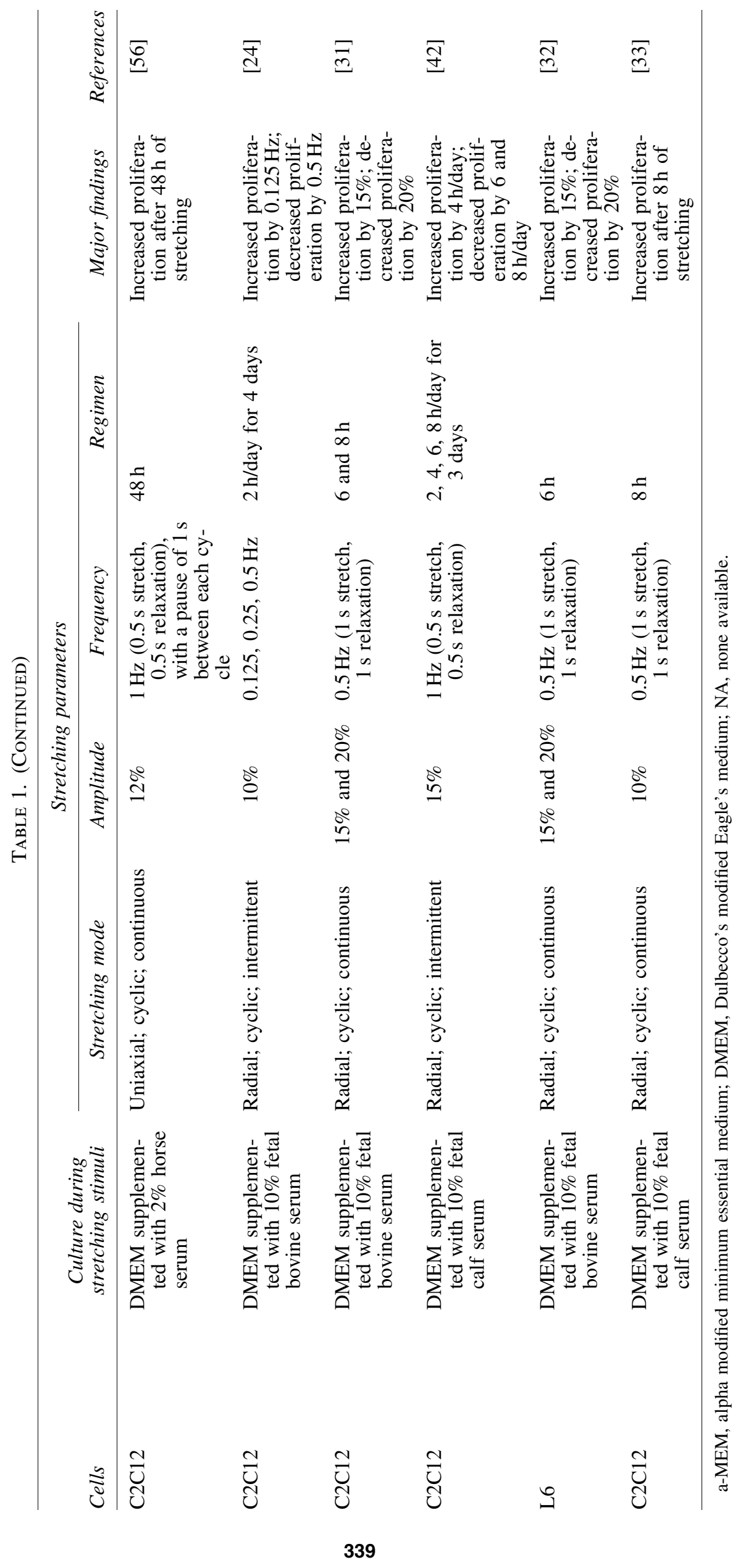


summary of these researches is present in Table 1. In this study, we listed some frequently implicated molecules by different studies, suggesting their role in stretch-regulated myoblast proliferation (Fig. 1).

\section{Nuclear factor-kappa B}

Kumar et al. [22] manifested the DNA-binding activity of nuclear factor-kappa B $(N F-\kappa B)$ was upregulated in mechanically stimulated $\mathrm{C} 2 \mathrm{C} 12$ myoblasts in a timedependent manner. Furthermore, they confirmed that $N F$ $\kappa B$ was essential in stretch-induced proliferation of $\mathrm{C} 2 \mathrm{C} 12$, since transfecting the $I \kappa B$ (inhibitor of NF- $\kappa \mathrm{B}$ ) completely restrained the elevated proliferation during $1 \mathrm{~h}$ stretch [22]. On the other hand, the indispensable role of $N F-\kappa B$ in expansion of $\mathrm{C} 2 \mathrm{C} 12$ myoblasts during longer duration of stretch ( $2 \mathrm{~h} /$ day for 2 and 4 days) was testified by using $N F-\kappa B$ specific inhibitors, Pyrrolidine dithiocarbamate and BAY11$7082[23,24]$.

Regarding the upstream events contributing to stretchactivated $N F-\kappa B$, Kumar et al. found that focal adhesion localized protein tyrosine kinases, such as focal adhesion kinase $(F A K)$ and $S r c$, led to the activation of Racl GTPase, which directly activated $N F-\kappa B$ [22]. In addition, other GTPase such as rab5 and $G a_{i}$, were also activated in $\mathrm{C} 2 \mathrm{C} 12$ myoblasts by rapid stretching stimuli, in both strain magnitude and strain rate-dependent manners, presenting themselves as potential activators of $N F-\kappa B$ [25]. In addition to these, Ji et al. [26] corroborated that p38 mitogen-activated protein kinase $(M A P K)$ upregulated $N F-\kappa B$ transcriptional activity in $\mathrm{C} 2 \mathrm{C} 12$ myoblasts under stretching, partially through phosphorylation of $p 65$ subunit.

How does the activation of $N F-\kappa B$ in response to mechanical stretch lead to the proliferation of $\mathrm{C} 2 \mathrm{C} 12$ myoblasts? It has been shown that cyclin Dl and interleukin-6, two well-known mitogenic factors, contain $N F-\kappa B$-binding sites in their promotor regions and showed increased expressions in stretched C2C12s [22]. In addition, some MicroRNAs, such as miR378, miR331, miR5097, and miR1941, were reported to be regulated by NF- $\mathrm{\kappa B}$, being candidates in modulating stretch-induced C2C12 myoblast proliferation [24].

\section{Cyclooxygenase 2}

Cyclooxygenase 2 (COX2) is an immediate/early gene that is induced during cell injury and inflammation. Its specific inhibitor NS-398 suppressed uniaxial stretch-induced C2C12 proliferation, implying $\mathrm{COX} 2$ is involved in propelling $\mathrm{C} 2 \mathrm{C} 12$ myoblast proliferation in response to stretching [23]. Notably, even though $C O X 2$ has $N F-\kappa B$-binding sites in its promoter region, COX2 was not a downstream factor of $N F-\kappa B$ [23]. Another research reported the implication of $C O X 2$ in radial stretch-induced $\mathrm{C} 2 \mathrm{C} 12$ proliferation by treating $\mathrm{C} 2 \mathrm{C} 12$ cells with $\mathrm{COX} 2$ inhibitor SC-236 or by using $\mathrm{COX}^{-1-}$ myoblasts [27]. Moreover, they proposed prostaglandin E2 and F2alpha as downstream effectors of $C O X 2$ pathway, since supplementing

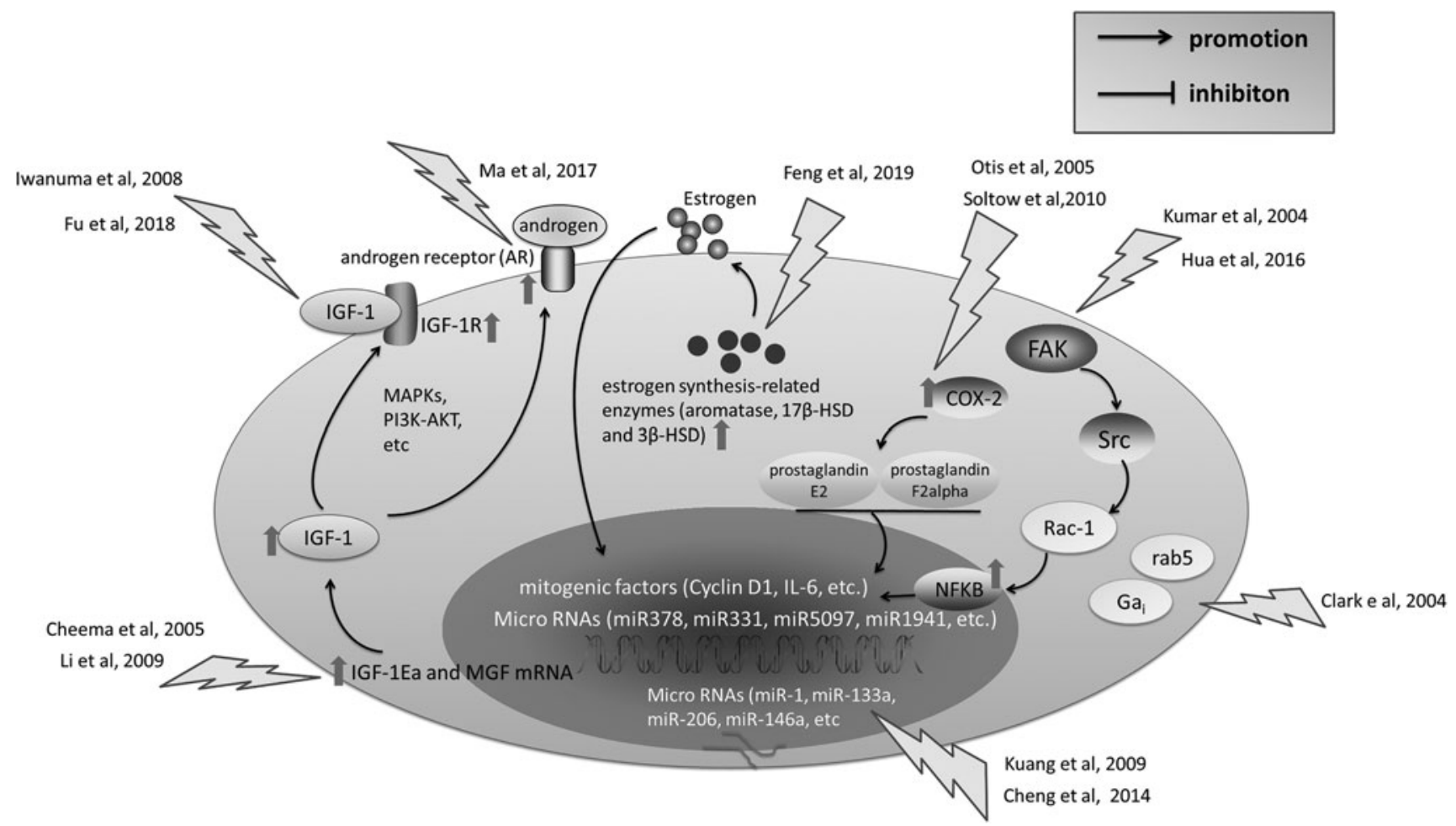

FIG. 1. Major molecules and pathways involving in the proliferation of myoblast during stretching stimuli. Several pathways mediated the stretch-induced myoblast proliferation, such as FAK-Src-Rac-NF- $\mathrm{BB}, \mathrm{COX} 2$, IGF-1, and some hormone-related pathways like androgen and estrogen. In addition to these, some micro-RNAs were also shown to positively regulate myoblast proliferation. It remains elusive whether there were more than one of these pathways being activated at the same time during stretch-mediated myoblast proliferation and what type of stretch may specifically activate one particular pathway. FAK, focal adhesion kinase; COX2, cyclooxygenase 2; IGF-1, insulin-like growth factor-1; NF- $\mathrm{BB}$, nuclear factor-kappa B. 
stretched $\mathrm{COX}_{2}^{-1-}$ myoblasts with prostaglandin E2 or F2alpha partially rescued the inhibited proliferation [27].

\section{Insulin-like growth factor-1}

Insulin-like growth factor-1 (IGF-1) is a growth factor that functions by binding to its receptor $I G F-1 R$. Iwanuma et al. [28] found that $I G F-1 \mathrm{mRNA}$ and protein expressions were elevated in $\mathrm{C} 2 \mathrm{C} 12$ cells during the early stage $(12$ and $24 \mathrm{~h}$ ) of mechanical stretching, and decreased in late stage (36 and $48 \mathrm{~h}$ ). Furthermore, C2C12 proliferation rate was highly correlated with $I G F-1$ level in their study, suggesting a potential function of IGF-1 in promoting $\mathrm{C} 2 \mathrm{C} 12$ expansion during strain. Consistently, the study by $\mathrm{Li}$ et al. [29] also observed that cell number of primary rat myoblasts commensurate with IGF-1 mRNA level when stretched for $0.5,1,2,4,8$, and $24 \mathrm{~h}$. Importantly, two isoforms of IGF-1 (IGF-IEa and mechano growth factor, also known as $M G F$ ) displayed distinct mechanical responses, and only $M G F$ is responsible for the stretchelevated myoblast proliferation $[29,30]$.

On the other hand, the downstream events of IGF-1 signaling were reported to be PI3K-AKT and MAPKs ( $p 38$, $E R K)$, the inhibition of which blocked stretch-induced C2C12 and L6 myoblast proliferation [31,32].

\section{Hormone-related genes}

The anabolic action of testosterone is mediated by intracellular androgen receptor $(A R)$. Ma et al. [31] showed that $A R$ expression was elevated by $15 \%$ stretch, accompanied with increased $\mathrm{C} 2 \mathrm{C} 12$ proliferation, which was suppressed by $A R$ inhibitor. On the other hand, estrogen level is also associated with muscle function and metabolic disorders, and $\mathrm{C} 2 \mathrm{C} 12$ myoblast expressed raised levels of estrogen synthesis-related enzymes, including aromatase, $17 \beta-H S D$, and $3 \beta-H S D$, in response to mechanical stretching [33]. In addition, the cell proliferation was positively correlated with the level of estrogen [33]. Whether these estrogen synthesis-related enzymes play crucial roles in prompting expansion of stretched myoblasts remains to be determined by the use of their specific inhibitors.

\section{Micro RNAs}

Three muscle-specific Micro RNAs (miR-1, miR-133a, and $m i R-206)$ are essential for proliferation and differentiation of skeletal myoblasts [34,35]. Moreover, when human primary skeletal myoblasts were mechanically stimulated for $1 \mathrm{~h}$, the expressions of these miRNAs were increased in $8 \%$ horse serum culture while decreased in $2 \%$ horse serum culture [36]. Another study found that miR-146a was upregulated in $\mathrm{C} 2 \mathrm{C} 12$ cells upon $48 \mathrm{~h}$ cyclic stretch, accompanied by increased proliferation and repressed level of Numb that could facilitate myogenic differentiation. Inhibition of miR-146a rescued the expression of Numb at the cost of compromised proliferation [37].

In addition to these miRNAs, other miRNAs, such as miR500, miR1934, miR378, miR31, miR331, miR5097, and miR1941, were also reported to be regulated by mechanical stretching of $\mathrm{C} 2 \mathrm{C} 12$ myoblasts, as we mentioned above to be downstream factors of $N F-\kappa B$ [24].

\section{Protein translation initiation and elongation}

It is well known that cell proliferation is accompanied with activation of anabolic pathways and increased protein syn- thesis. Thus, mechanical stimuli play a major role in the regulation of skeletal muscle mass by stimulating both myoblast proliferation and protein synthesis. Nakai et al. [38] demonstrated that static or cyclic uniaxial stretch activated p70 S6 kinase $(p 70 S 6 K)$ and eukaryotic elongation factor 2 (eEF2), which are the makers for protein translation initiation and peptide chain elongation, respectively.

Furthermore, mammalian target of rapamycin ( $m T O R)$ was shown to act upstream of $p 70 S 6 K$ and $e E F 2$ activation during stretching of myoblasts. Inhibition of $m T O R$ not only prohibited translation initiation, but also induced apoptosis in myoblasts under mechanical tension [38,39]. One mechanism considering the activation of $m T O R$ in stretched myoblasts is the phosphorylation of some tyrosine kinases under stretching stimuli [38]. Another potential candidate regulating $m T O R$ in myoblasts exposed to mechanical stretch is regulated in development and DNA damage responses 2 (REDD2), which is enriched in myoblasts and negatively regulated $m T O R$ signaling by associating with 14-3-3 protein and releasing tuberous sclerosis complex 2 from the inhibition of 14-3-3 [40].

\section{Repressed myoblast proliferation by intensive stretch}

Notably, the reported mitogenic effect of mechanical stretch on myoblast is largely because of the optimized experimental conditions (magnitude, frequency, duration). For example, $0.5 \mathrm{~Hz}$ cyclic stretch at the magnitude of $15 \%$ propelled myoblast proliferation, whereas $20 \%$ magnitude stretch impeded it [31]. Similarly, another study applied the static stretch at the magnitude of $1 \%, 4 \%$, and $168 \%$, and demonstrated that myoblast proliferation was provoked by $1 \%, 4 \%$, but hindered by $168 \%$ stretch [41]. Hua et al. found that $10 \%$ cyclic stretch at $0.125 \mathrm{~Hz}$ rendered proliferation, but $0.5 \mathrm{~Hz}$ cyclic stretch obstructed it [24]. With regard to stretching duration, Feng et al. [42] showed that C2C12 proliferated most rapidly at $4 \mathrm{~h}$ of cyclic stretch, whereas the proliferation rate started to attenuate after longer exposure (6 and $8 \mathrm{~h})$ to stretch.

\section{Biphasic Effect of Stretch on Skeletal Myoblast Differentiation}

Myoblast differentiation is initiated when myoblasts irreversibly withdraw from the cell cycle and start to express muscle-specific genes, some of which will be discussed in this study because of their mechanosensitive properties. In addition, it should be noted that mechanical strain has both positive and negative effects on myoblast differentiation, as will be displayed in Table 2 and Fig. 2.

\section{Myogenic regulatory factor transcription factors}

Myogenic regulatory factors (MRFs), including Myod, Myog, MRF4, and Myf5, induce transcriptions of musclespecific target genes by binding to the $\mathrm{E}$ box in the promoters of these genes [43]. MRFs were mechanosensitive genes in myoblasts, and some studies manifested increased levels of MRFs, such as Myog [44-50], Myod [44,46,48,50], Myf5 [49,50], and MRF4 [50], in C2C12 cells under stretching stimulation, accompanied by accelerated myogenic differentiation. On the other hand, mechanical stretch was also 


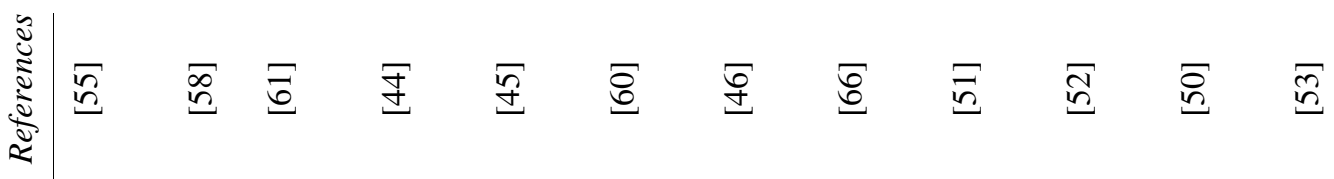

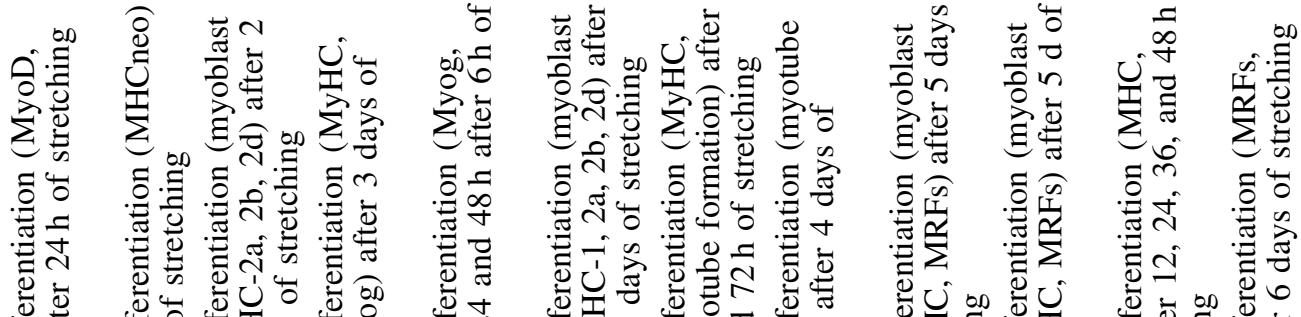

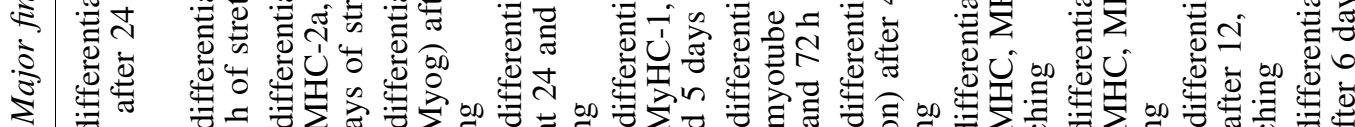

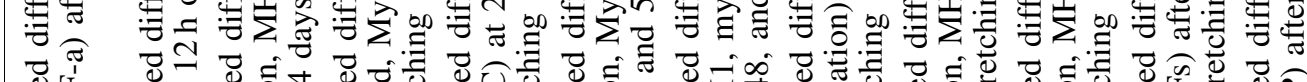

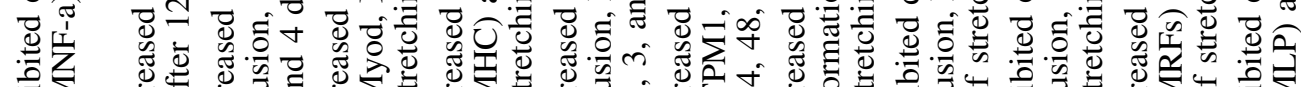

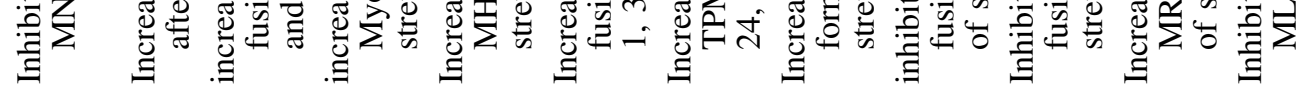

$m \infty$

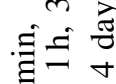

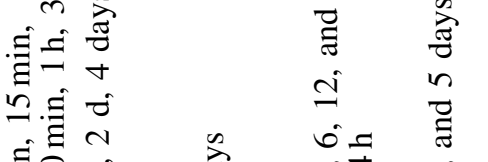

i

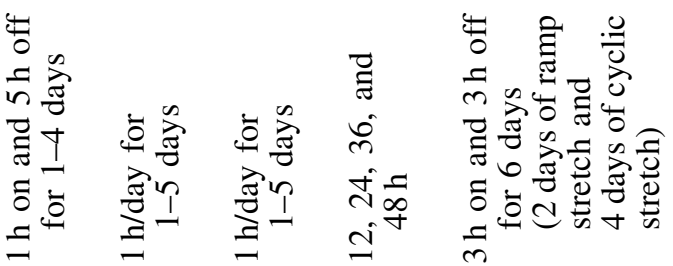

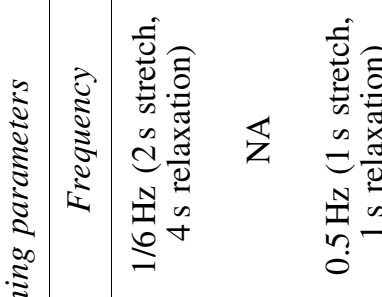

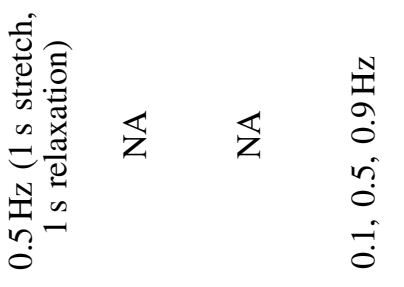

0
ज्ञ
0
0
0
0
0

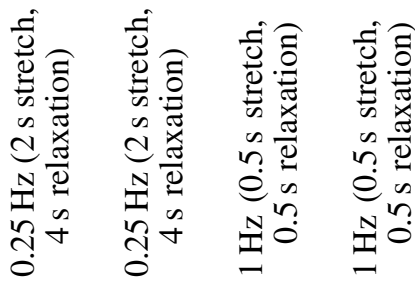

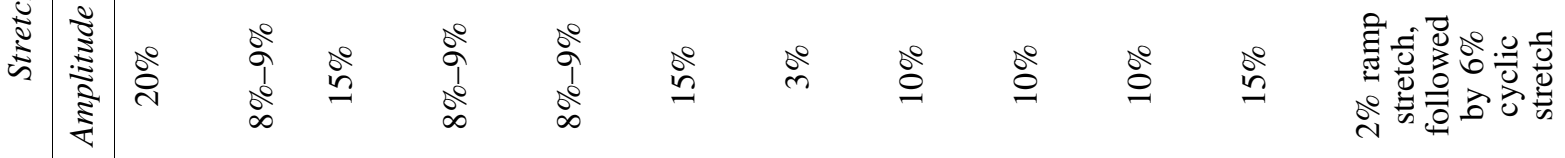

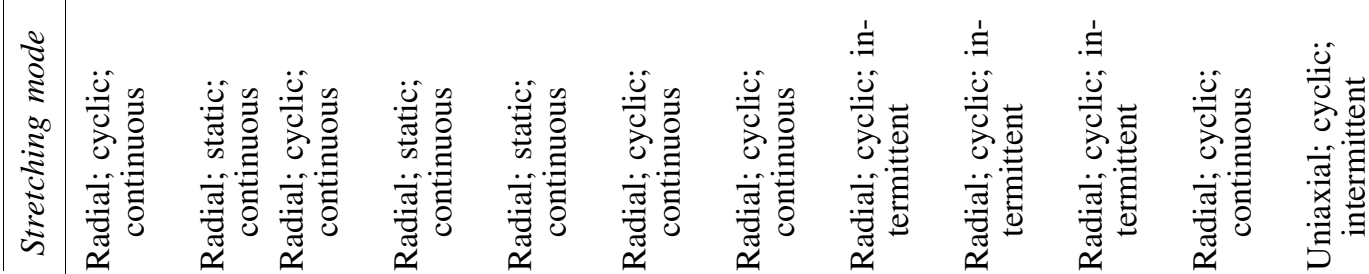

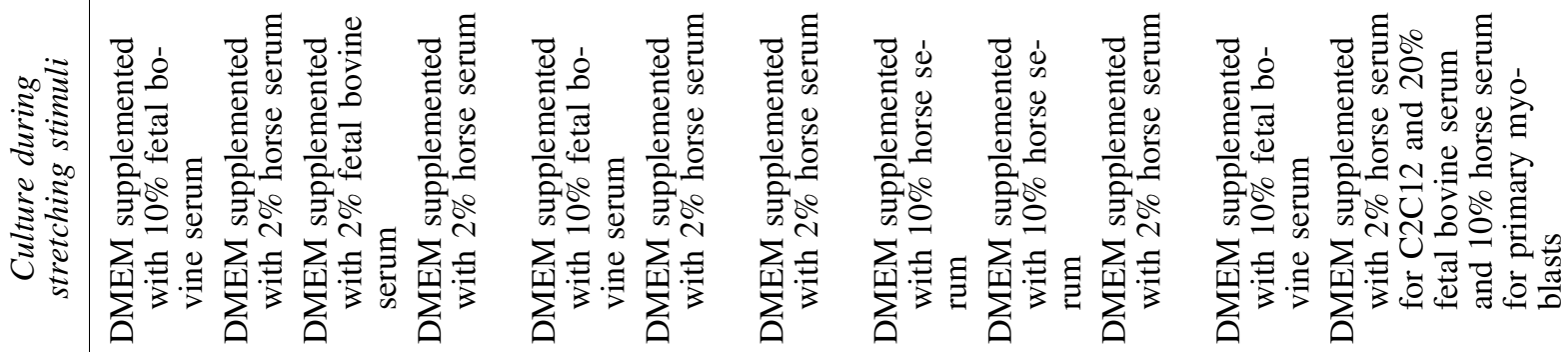

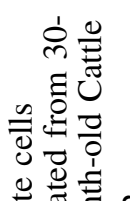

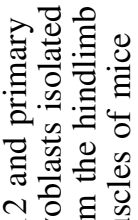

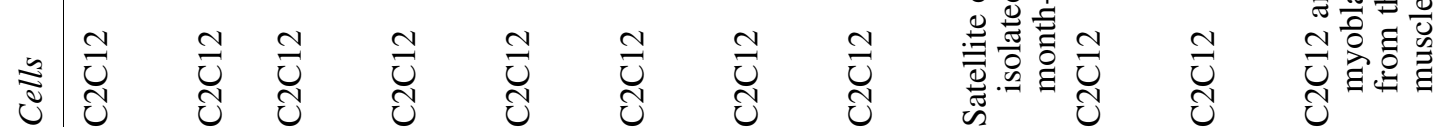




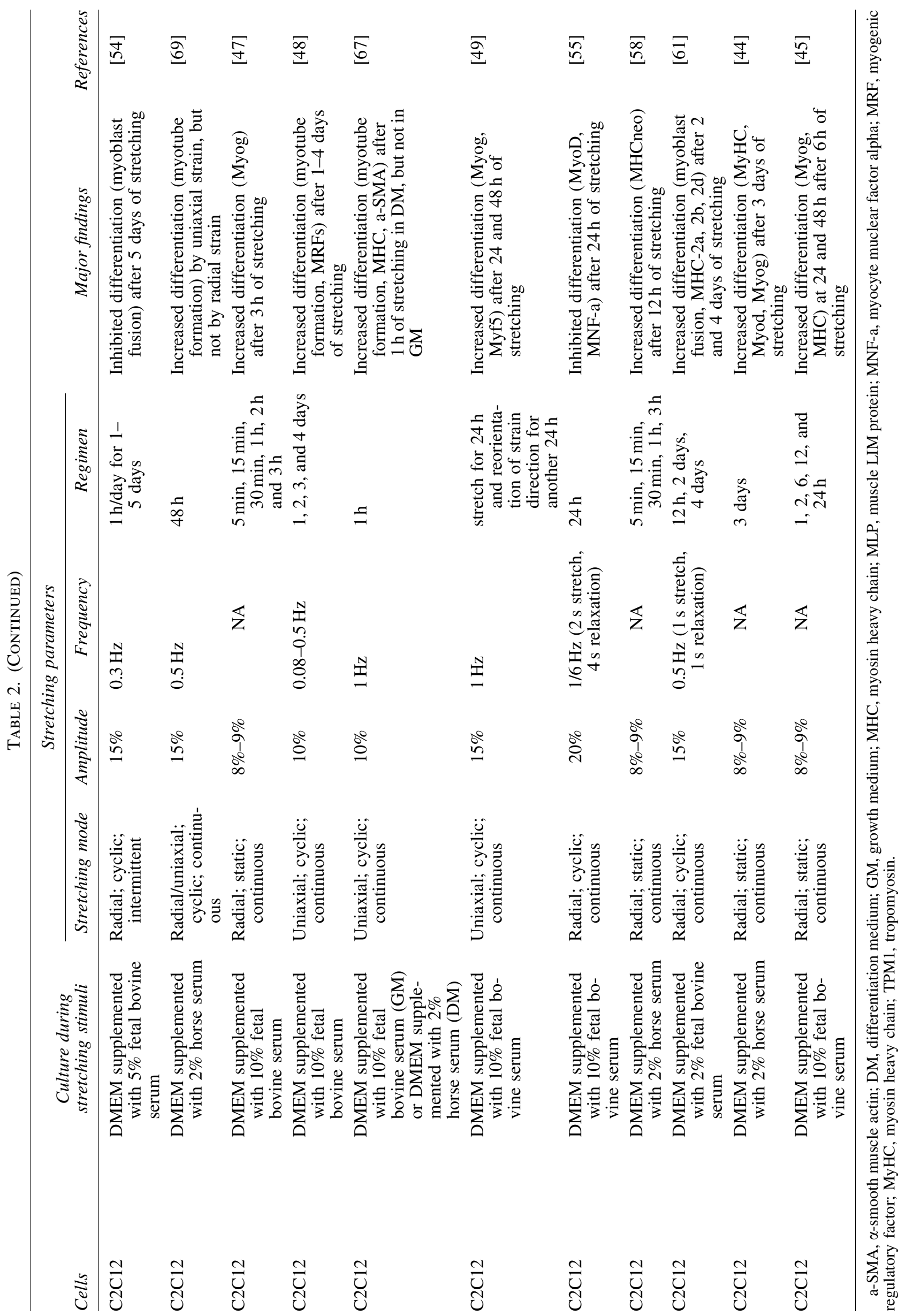




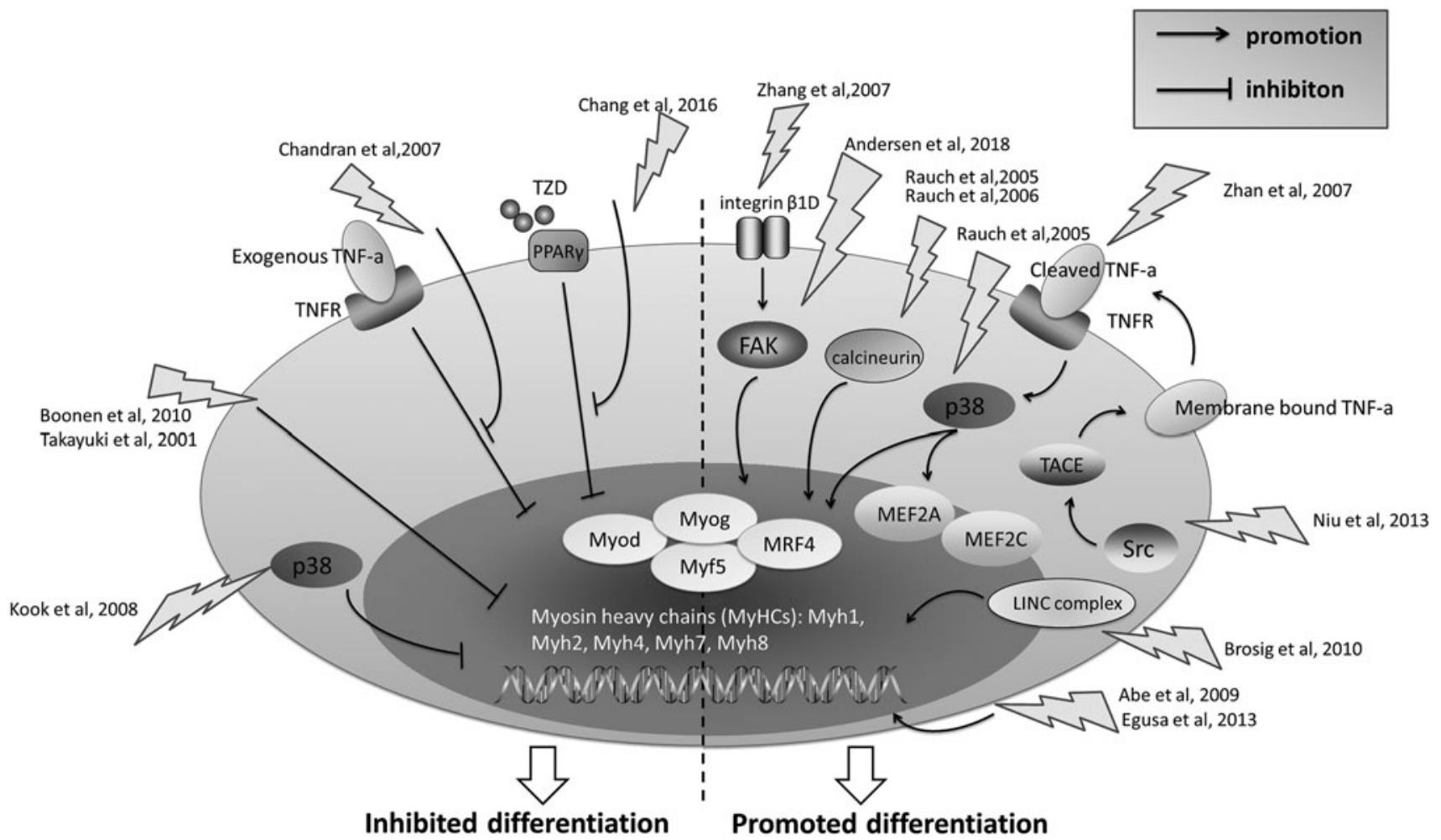

FIG. 2. Major molecules and pathways involving in the myogenic differentiation of myoblast during stretching stimuli. Several pathways were reported to promote myoblast differentiation under various stretching stimuli, such as integrin $\beta 1 D-$ FAK, calcineurin, p38 MAPK, Src-TACE-TNF $\alpha$. The activation of MRF and MEF2 transcription factors might act downstream of these pathways and directly induce transcriptions of muscle-specific genes. On the other hand, p38 MAPK, and $\mathrm{TNF} \alpha$ pathways were also reported to inhibit myoblast differentiation under some specific mechanical conditions. Moreover, mechanical stretch could antagonize the effect of inhibitors of myogenesis such as PPAR agonist TAD and exogenous TNF $\alpha$. Altogether, mechanical stretch has dual effects (promotion or suppression) on myoblast differentiation. TNF $\alpha$, tumor necrosis factor $\alpha$; MRF, myogenic regulatory factor; MEF2, myocyte enhancer-binding factor 2; TACE, TNF $\alpha$-converting enzyme; MAPK, mitogen-activated protein kinase; PPAR, peroxisome proliferator-activated receptor.

reported to repress the expressions of these $M R F s$, such as Myog [27,37,51-54] and Myod [51-55], which was consistent with impaired myogenic differentiation of $\mathrm{C} 2 \mathrm{C} 12$ cells. In addition, Dugan et al. [56] reported that both Myog and Myod were unaffected by mechanical stretch, but maturation of myotubes was perturbed.

The contradictory results of these published literatures could not simply be attributed to stretching parameters alone (static/cyclic, radial/uniaxial, continuous/intermittent, long/ short duration). Instead, we insisted that the culturing status of myoblasts, such as constituent of culturing medium and stages of myogenic differentiation, have a synthetic effect on myoblast differentiation. In addition, different sources of myoblasts (rat, mouse, calf) used in these studies may also account for the various responses to mechanical stretch. In spite of these, the mechanisms of the multifaceted effects of stretch on the expressions of these $M R F s$ remain to be elucidated.

\section{Myocyte enhancer-binding factor 2 transcription factors}

Myocyte enhancer-binding factor 2 (MEF2) proteins, such as $M E F 2 A, 2 B, 2 C$, and $2 D$, function as accessory regulators of muscle gene expression, through physically binding and cooperating with $M R F s$ [57]. Similar to $M R F s$, mechanical stretch also positively regulated $M E F 2 A[46,58]$ and $M E F 2 C$ [45] expressions in C2C12 myoblasts. Particularly, MEF $2 A$ phosphorylation and subsequent nuclear translocation is critical for $M E F 2 A$ to exert its function [58]. Still, another study found that $M E F 2$ phosphorylation was unchanged during mechanical stretching [44]. Based on these results, it will be interesting to systematically investigate how does a specific type of stretch affect the expressions of both $M R F s$ and $M E F 2$ proteins, as well as their interactions in myoblasts, as this will fully interpret the myogenic differentiation by mechanical stretch.

\section{Myosin heavy chains}

Myosin heavy chains ( $M y H C s$ ), encoded by $M y h$ genes, are muscle contraction proteins that consist of many isoforms [59]. The changed expressions of these isoforms are indicative of muscle development, metabolism, and function. Some studies displayed either increased or decreased mRNA levels of $M y h 1$ (MyHC-2D or $M y H C-2 X)[46,53,60,61], M y h 2(M y H C-2 A)$ [46,50,53,60,61], Myh4 (MyHC-2B) [46,53,60,61], Myh7 (MyHC- $\beta$ or $M y H C-1)$ [60], Myh8 (MyHC-neo) [53], in myoblasts under stretching stimuli. Notably, the changed levels of these $M y h$ genes concur with the biphasic effect of stretch on myoblast differentiation. On the other hand, other 
studies demonstrated stretch could also induce $M y H C$ protein expressions, accompanied by enhanced myoblast differentiation $[44,45]$.

The upstream pathways regulating the $M y h$ genes expressions in myoblasts under mechanical environment were $p 38$ kinase and calcineurin phosphatase $[44,58]$. Since aforementioned $M R F s$ and $M E F 2 s$ are direct transcriptional regulators of these $M y h$ genes, it is reasonable to deduce stretching stimuli regulate $M y h$ expressions mainly through $p 38$ and calcineurin-dependent activation of $M R F s$ and $M E F 2 s$.

\section{p38 MAPK}

$M A P K \mathrm{~s}$ are well-known transducers of extracellular mechanical stimuli in various cell types [62]. In particular, one major component of $M A P K s$, the $p 38 M A P K$, is crucial in myoblast biology (see review refs. $[63,64]$ ). Notably, a lot of researches explored potential roles of $p 38$ in mediating myoblast differentiation under mechanical stretching. The upstream events of stretch-activated $p 38$ in myoblasts was $S r c-T A C E-T N F \alpha$ pathway $[45,47]$. In detail, the synthesized tumor necrosis factor alpha $(T N F \alpha)$ is cleaved and released as a secreted form of $T N F \alpha$ that could directly activate $\mathrm{p} 38$ by binding to $T N F \alpha$ receptor [45]. This cleaving process is catalyzed by TNF $\alpha$-converting enzyme $(T A C E)$, which is phosphorylated by tyrosine kinase Src under mechanical strain [47].

Regarding the downstream factors of p38 in mediating stretch-induced myogenic differentiation, Rauch and Loughna [58] found that MEF2A, MEF2C, Myog, p21, and $M y h$ were all activated in a $p 38$-dependent manner [45].

However, it is still a debate whether $p 38$ positively or negatively regulate myogenic differentiation under mechanical environment. For example, mechanical stretch was shown to inhibit both $p 38$ phosphorylation and bovine satellite cell myogenic differentiation, implying a positive effect of $p 38$ on myogenic differentiation [51]. Another study by the same authors confirmed persistent $p 38$ activation during stretching of $\mathrm{C} 2 \mathrm{C} 12$ myoblasts, and inhibitors of $p 38$ promoted myogenic differentiation, thus manifesting the negative role of $p 38$ in regulating myogenic differentiation [52]. Thus, p38 has multifaceted effects on myogenic differentiation in various myoblasts.

\section{Cytoskeleton-related proteins}

Normally, cells respond to external mechanical stimuli by activation of signaling pathways that often lead to cytoskeletal contraction [65]. Integrin $\beta 1 D$ was identified as an indispensible component of the cytoskeleton-related pathways mediating myogenic differentiation in mechanical microenvironment [66]. Increased integrin $\beta 1 D$ expression in $\mathrm{C} 2 \mathrm{C} 12$ cells by mechanical stretch activated downstream cytoskeletal signaling proteins $F A K$ and $R h o A$, and knocking down integrin $\beta 1 D$ inhibited $\mathrm{C} 2 \mathrm{C} 12$ differentiation [66]. On the other hand, Andersen et al. found that activation of $F A K$ is necessary for the myoblast differentiation, since $F A K$ inhibition compromised the stretch-prompted myogenic differentiation [49].

In addition to these proteins located on cell surface or cytoplasm, other family of proteins anchoring in the outer nuclear membrane connected actin cytoskeleton to the nuclear lamina, providing a continuous structure between ECM and nuclear lamina. For example, the integrality of LINC complex (the bridge across the nuclear membranes Linking the Nucleus with the Cytoplasm) ensured myoblast proliferation, rather than differentiation, under mechanical stimuli. Disruption of this complex (transfecting cells with dominantnegative Sun1 and Nesprin-2) reversed the effect of stretch, with abrogated proliferation and induced differentiation [54].

\section{The antagonizing effects of stretch on inhibitors of myogenesis}

Mechanical stretching of myoblasts has been shown to antagonize the inhibitory effect of some drugs on myoblast differentiation. For example, thiazolidinedione (TZD), a specific agonist for peroxisome proliferator-activated receptor $\gamma$, suppressed the $\mathrm{C} 2 \mathrm{C} 12$ myogenic differentiation, whereas application of cyclic stretch rescued the inhibitory effects of TZD [67]. Another case is reported by Chandran et al., who verified that exogenous added TNF $\alpha$ impeded the myoblast differentiation, while mechanical stretch acted as potent inhibitors of the intracellular actions of $\mathrm{TNF} \alpha$ by inducing muscle cell differentiation in a proinflammatory environment [46].

\section{Stretching-induced myoblast differentiation in muscle tissue engineering}

Restoration of muscle mass and function is critical in muscle tissue engineering. Moon du et al. [68] developed a mechanical strain device to cyclically stretch human skeletal muscle cellseeded three-dimensional scaffolds before implantation onto the latissimus dorsi muscle of mice. They found that prestretching myoblast scaffolds not only produced viable muscle tissue constructs with maturely developed multinucleated muscle fibers, but also generated tetanic and twitch contractile responses [68]. This demonstrated the importance of stretching preconditioning in vitro to accelerated skeletal myoblast differentiation, maturation, and function in vivo.

\section{Uniaxial versus equibiaxial stretch on myoblast differentiation}

Almost all the studies above explored the effects of one specific type of stretch on myoblast differentiation, using either uniaxial or equibiaxial stretching. Intriguingly, one study by Pennisi et al. compared the distinct impacts of uniaxial and equibiaxial $15 \%$ cyclic tensile stretch (CTS, $0.5 \mathrm{~Hz}$ ) on myogenic differentiation [69]. According to their conclusion, uniaxial CTS drives $\mathrm{C} 2 \mathrm{C} 12$ differentiation while equibiaxial CTS does not favor the differentiation process. However, even though some of the studies above corroborated this statement $[48,49,51,52,54,55,67]$, other literatures seemed to display opposed results. In detail, some authors revealed the accelerated myoblast differentiation in response to equibiaxial stretch $[44-47,58,60,66]$, while others uncovered dampened or unaffected myoblast differentiation by uniaxial stretch $[53,56]$.

Collectively, it should be concluded that these contradictory results actually reflected that mechanoresponses of myoblasts vary with the subtle changes of cellular microenvironment, such as types of stretch (cyclic/static, uniaxial/ equibiaxial, intermittent/constant), as well as culturing conditions and sources of cell, etc. 


\section{Effect of Stretch on Skeletal Myoblast Mechanical Resistance, Survival, and Death}

\section{Genes regulating mechanical properties of myoblasts}

When cells were stretched, the morphological extending of cell body is always accompanied by reorganization of cytoskeleton. In this regard, the accurate balance between stiffness and plasticity of cytoskeleton is critical for myoblasts to withstand and survive during physical stretching, as well as to adapt to mechanical microenvironment. One important gene in mechanosensing and making cytoskeletal adaptations is the LMNA gene (which encodes lamin A/C protein) [70]. LMNA (-/-) myoblasts are unable to resist mechanical stretching, leading to severe intracellular damage to the cytoskeleton, which was due to abnormal activation of yes-associated protein signaling [70]. This suggest that cytoskeletal plasticity and adaptability to ECM mechanical cues requires a functional lamin $A / C$ network.

Other reported gene candidates in mediating cytoskeletal elasticity and rigidity in myoblasts are focal contact proteins talin and vinculin [71]. Zhang et al. found that static stretch enhanced the elastic modulus ( $\left.E_{\text {app }}\right)$ of $\mathrm{C} 2 \mathrm{C} 12$ cells, through $\mathrm{NO}$-induced increase in talin and vinculin expressions and decrease in calpain-mediated talin proteolysis [71].

In addition, integrin $\beta 1 D$ was also involved in stretch-induced $E_{\text {app }}$ elevation in $\mathrm{C} 2 \mathrm{C} 12$ cells, since integrin $\beta 1 D$ knockdown prohibited the increased $E_{\text {app }}$ [66]. Another intriguing study by Mitsui et al. [72] displayed a time lapse sequence of stiffness distributions of living myoblasts by scanning probe microscopy when cells were stretched intermittently. They proposed that myoblasts have tensional memory effect to maintain cytoskeletal tensional homeostasis, based on the observation that cell stiffness was increased instantly after stretching but gradually decrease and return to its original level. In addition, this memory effect, which largely depends on the duration, rather than the magnitude of stretching, might be related with phosphorylation level of myosin II regulatory light chain [72].

\section{Relationship between cytoskeletal stiffness and myoblast death under stretching}

On the other hand, we could easily assume that cellular damage occurs when mechanical stretch is too severe for myoblast cytoskeleton to resist and adapt, which is often seen in muscle fiber degeneration in a number of myopathies due to higher mechanical vulnerability of skeletal muscle fibers during muscle contraction [73]. Accordingly, a study by Wang et al. [74] investigated the role of $F$-actin in the survival ratio of $\mathrm{C} 2 \mathrm{C} 12$ myoblasts under $30 \%$ uniaxial stretch for $30 \mathrm{~min}$. They found that some $\mathrm{C} 2 \mathrm{C} 12$ cells died during stretching, while lowering the tension of cytoskeleton or disassembling $F$-actin with drugs (Blebbistatin and cytochalasin D) increased the survival rate of myoblasts. Furthermore, myoblasts with thinner morphology had more stable peripheral $F$-actin than wider ones, thus possessing more viability under stretching than wider ones [74].

Goldmann and colleagues also explored the involvement of cytoskeleton of human and mouse myoblasts in resisting mechanical stretching-induced cellular damage [75,76]. Desmin is a muscle-specific intermediate filament (IF) protein, the mutation of which is associated with desminopathies. By transfecting human myoblasts with a genetically heterozygous
R350P desmin mutation (DesR350P), Bonakdar et al. [75] found that DesR350P myoblasts exhibit increased cell stiffness, and thus reduced cell viability in response to mechanical stretch. Consistently, other studies also demonstrated the crucial position of desmin in regulating the cytoskeletal rigidity through overexpressing mutant desmin E413K and $\mathrm{R} 349 \mathrm{P}$ in mouse myoblasts $[77,78]$.

In addition, plectin, a giant $(4,500 \mathrm{kDa})$ cytolinker protein, anchors IFs to ECM/adhesion complexes. Interestingly, plectin-deficient mouse myoblasts had lower mechanical vulnerability upon mechanical stretch compared with wildtype cells, which was attributed to lower cellular stiffness [76]. Altogether, these studies demonstrated that cytoskeletal filament systems are sensitive to physical stretching of cells, the disruption of which directly affect the survival and death of myoblasts under mechanical stretching.

\section{Molecular mechanisms of stretch-induced myoblast death}

During the last decade, our team had thoroughly investigated how does mechanical stretch lead to myoblast apoptosis and which signaling pathways are involved. We used two skeletal myoblast cell lines, L6 and C2C12, to study the effect of cyclic stretch with different loading magnitudes and durations on apoptosis of these cells.

First, caspase-3 was the direct motivator of myoblast apoptosis in both stretching magnitude- and stretching durationdependent manners $[79,80]$. Subsequently, two major organelles, endoplasmic reticulum (ER) and mitochondria, were reported to mediate stretch-activated caspase-3 pathway. Caspase-12, a specific ER-residual caspase, was cleaved at Asp94 during ER stress, which was a prerequisite to the caspase-3 activation and myoblast apoptosis [81]. Inhibition of caspase-12 by either nonspecific inhibitors or caspase-12-specific siRNA could partially rescue the myoblast death under stretching stimuli $[81,82]$. Apart from these, miR-147 was also found to be related with stretch-induced ER stress and myoblast apoptosis by targeting breast cancer metastasis suppressor 1 during mechanical stretching of L6 myoblasts. Stretching stimuli suppressed $m i R-147$ expression, thus favoring ER stress and apoptosis of myoblasts [83].

On the other hand, mitochondrion was another important organelle involving in stretching-induced myoblast death, with mitochondrial maker protein apoptosis-inducing factor (AIF) level being elevated during mechanical stretch [84]. Furthermore, we found a stretching magnitude-dependent increment of reactive oxygen species (ROS) in $\mathrm{C} 2 \mathrm{C} 12$ myoblasts, which activated two pathways that contribute to myoblast death: $J N K$ and $p 53[85,86]$. When ROS was inhibited, stretch-activated $J N K$ was also attenuated; inhibition of both ROS and $J N K$ could alleviate myoblast apoptosis under stretching stimuli [85]. Furthermore, ROS-induced p53 mitochondrial translocation only occurred when ROS was overaccumulated by stretching stimuli, which was a critical event leading to myoblast apoptosis, possibly depending upon classical mitochondrial apoptotic pathways [86].

\section{Effect of Stretch on Properties of Plasma Membrane of Skeletal Myoblasts}

It could be easily accepted that when myoblasts are mechanically stretched, the PM should be the first structure being 
affected, and therefore, the mechanoresponse of PM is critical in initiating the following cellular changes (behaviors, structures, functions, gene expressions, etc.) during mechanical stretching. Caveolae are flask-like invaginations of the PM that is organized by caveolins. By briefly stretching myoblasts (1 min), Gervasio et al. proposed that stretch induced reversible folding and unfolding of caveolae and activation of Src kinase. Furthermore, overexpression of caveolin-3 potentiated the stretch-evoked activation of $\operatorname{Src}$ kinase in myoblasts. These results were attributed to the redistribution of caveolin3 from intracellular pools to cell surface [87]. Thus, the dynamical changes of these microstructures on PM might reflect the initial responses of myoblasts to mechanical stretch.

On the other hand, Leopold and Gefen explored the permeability of the PM of myoblasts being radially or uniaxially stretched. Using a wide range of stretching magnitude from $3 \%$ to $12 \%$, they suggested that mechanical deformation of PM induced some nonspecific pores/tears in PM, the number and size of which increased in a magnitude-dependent manner [88,89]. This will allow for the build-up of intracellular concentrations of biomolecules (ions, metabolites, free radicals, hormones, etc.) that are present at the extracellular space, leading to metabolic changes to cells. Specifically, $\mathrm{O}_{2}$ transport in $\mathrm{C} 2 \mathrm{C} 12$ myoblasts (either $\mathrm{O}_{2}$ influx into cells or loss of intracellular $\mathrm{O}_{2}$ ) became faster with the increasing levels of stretching magnitude, due to either increased PM permeability or cell surface area [90].

\section{Effect of Stretch on Multipotency of Transdifferentiation of Skeletal Myoblasts}

It has been reported that skeletal myoblasts possess pluripotent differentiation potential in vitro and in vivo [91]. Mechanical stretch, as a unique external stimulus, has been proposed to affect the pluripotency of skeletal myoblasts. For example, coculture of skeletal myoblasts with cardiomyocytes promoted skeletal myoblasts to express cardiac-specific proteins such as cardiac troponin $\mathrm{T}$, atrial natriuretic peptide, $N k x 2 E$, and GATA4, which was inhibited by addition of nifedipine or culture in $\mathrm{Ca}^{2+}$-free media. Stretching the skeletal myoblasts cocultured with cardiomyocytes completely restored this inhibitory effect and promoted transdifferentiation into cardiomyocytes [92].

Another research confirmed that $\mathrm{C} 2 \mathrm{C} 12$ cells differentiate into adipocytes in adipogenic induction medium, while mechanical stretch prohibited this process through Wnt signaling [93]. In addition, Kim et al. found that bone morphogenetic protein $2(B M P-2)$ treatment enhanced the gene expression of osteogenic markers ( $A L P$, type I collagen, osteopontin, osteocalcin, cbfal, osterix, and $d l x 5)$ in $\mathrm{C} 2 \mathrm{C} 12$ myoblasts. $B M P-2$ combined with mechanical stretching of $\mathrm{C} 2 \mathrm{C} 12$ further potentiated the expressions of these genes, demonstrating the positive effect of stretch on osteodifferentiation of myoblasts [41].

Collectively, these studies corroborated two points in common: (1) skeletal myoblasts possess the multipotency of transdifferentiation into other types of cells when cultured in special conditions, and (2) mechanical stretching either positively or negatively affected the progressing of myoblast transdifferentiation.

\section{Effect of Stretch on Reorientation and Alignment of Skeletal Myoblasts}

It has been demonstrated that skeletal myoblast orientation and internal cell structure displayed dynamical changes in response to mechanical stretch, largely depending on the direction of the stretch. To realign themselves from a randomly aligned state, skeletal myoblasts first need to be able to migrate. One study conducted by Marom et al. found that radial stretch combined with exogenous sodium pyruvate (NaPy) supplements accelerated $\mathrm{C} 2 \mathrm{C} 12$ migration rate, in contrast to control group only supplemented with NaPy [94]. Subsequently, Ahmed et al. explored the adaptive responses of $\mathrm{C} 2 \mathrm{C} 12$ skeletal myoblasts seeded on fibronectin lines with different orientations relative to the stretching direction. After application of uniaxial stretch (amplitude of 7\%, frequency of $0.5 \mathrm{~Hz}$ ), they found that actin fiber organization is predominantly controlled by stretch [95].

Another interesting study by Leccia et al. [96] recorded the dynamics of reorientation of C2C12 myoblasts after 1, 3, and 6 hours of uniaxial stretch (amplitude of 20\%, frequency of $0.3 \mathrm{~Hz}$ ). Cells retracted after the first stretching hour and started to spread again after $3 \mathrm{~h}$ of stretch. At $6 \mathrm{~h}$ of stretching, cells realigned themselves at the mean orientation of $66.5^{\circ}$ relative to the direction of stretch. Desmin plays a crucial part in this process, since $\mathrm{C} 2 \mathrm{C} 12$ myoblasts expressing mutant desmin D399Y failed to display the same mechanoresponses as control cells during stretch, leading to less retracting, spreading, and mean orientation angle [96].

Similarly, there were other two literatures reporting the reorientation of myoblasts being extended by uniaxial stretch $[48,49]$. However, both studies showed that myoblasts aligned orthogonal to the direction of stretch, in contrast to the orientation of $66.5^{\circ}$ in Leccia et al.'s [96] research. There is no clear illumination addressing this deviation among these studies. However, we suspected the stretching duration might partially account for this problem, since the study by Leccia et al. [96] applied stretching for $6 \mathrm{~h}$, while the studies showing perpendicular orientation stretched myoblasts for $24 \mathrm{~h}$ and 4 days, respectively.

Notably, all the researches above manifested uniaxial stretch-induced reorientation of myoblasts. By comparing uniaxial and equibiaxial stretches, Pennisi et al. further demonstrated that while myoblasts aligned vertically to the direction of stretch when extended uniaxially, they had no clear uniform orientation and displayed signs of membrane damage when extended equibiaxially [69].

\section{Contradictory Responses of Myoblasts to Mechanical Stretching}

The cellular responses of myoblasts to mechanical stimuli (proliferation, differentiation, apoptosis, etc.) seemed to be opposed to each other. One illumination is apparently because of different experimental designs, including stretching parameters and culturing conditions, which distinctly affect the intracellular signaling and gene expression profile, thus leading to substantially different reactions of myoblasts.

However, cell heterogeneity is also an ignored problem considering the multifaceted effect of stretching on myoblasts $[97,98]$. For example, in our previous studies, we had demonstrated that even though myoblast apoptotic rate increased in response to stretching of longer duration and higher magnitude, there were still some cells surviving after exposure to these intensive stretches. We suspected these cells might possess some "mechanical resistant" properties that are absent from the apoptotic cells, and possibly undergo proliferation or 
differentiation under these proapoptotic stretching conditions. Single-cell analysis will provide better insights into the complicated phenotypes of myoblasts during mechanical stimulation, considering cell heterogeneity as a factor contributing to multiple responses of cells to mechanical stimuli.

\section{Interconnections Among the Mechanosensitive Pathways in Myoblasts}

Notably, some pathways were frequently mentioned in different studies, such as $\operatorname{Src}[22,38,47,87], N F-\kappa B$ [2224,26,54,85], p38 [26,31,32,38,45,47,51,52,54,58], FAK [22,49,66], IGF-1 [28-32], NOS [16,21,23,46,66,71], AKT $[31,32,40,45,86]$, and $m$ TOR [38-40], in spite of various stretching parameters being used in these studies. To some extent, this suggests these pathways are more mechanosensitive, and are more easily activated during distinct type of mechanical strain. Furthermore, we could assume that under one specific mechanical stimulus, more than one of these pathways might be involved in transducing mechanical signal and in mediating cellular adaptations to external straining environment. Thus, understanding about the interconnections among these pathways should shed some light on the clear molecular mechanisms regulating the responses of myoblasts to mechanical stretching (Fig. 3).

\section{Perspectives}

Identification of molecules and pathways that integrate mechanoresponses of skeletal myoblasts will be an important key for unlocking a better understanding of the complex physiological and pathological changes of skeletal muscle under mechanical stimuli. During the past decades, substantial works have been done in progressing the knowledge of multiple responses of skeletal myoblasts to mechanical stretching, which will enhance our comprehension about the myoblast contributions to macroscopical muscular changes (structure, mass, function, etc.) during physical exercise, loading bearing, or medical treatment.

However, what remains elusive is the mechanisms by which all these genes and signaling pathways work together to give a unified response resulting in altered phenotypes and behaviors of skeletal myoblasts due to mechanical loading, as we have partially overviewed in the last part of this review. A more global view of integration of intracellular molecules and pathways is necessary for development of specific and effective countermeasures for maximizing the beneficial skeletal muscle changes while minimizing or ablating deleterious side effects during external mechanical loading. New technologies such as microarray analysis and single-cell analysis should pave the way for the study of skeletal myoblast mechanoresponses, rather than the examination of separate individual components, as had been done before. On the other hand, strain regimens comprising amplitude, duration, orientation, frequency, and rest period, should be optimized in search of a more advantageous mechanical environment that is conducive to skeletal muscle homeostasis.

Overall, a better understanding of myoblast biology during external stretching, appropriate countermeasures for the side effects of mechanical loading, and optimal straining environment will promote the developments of muscular

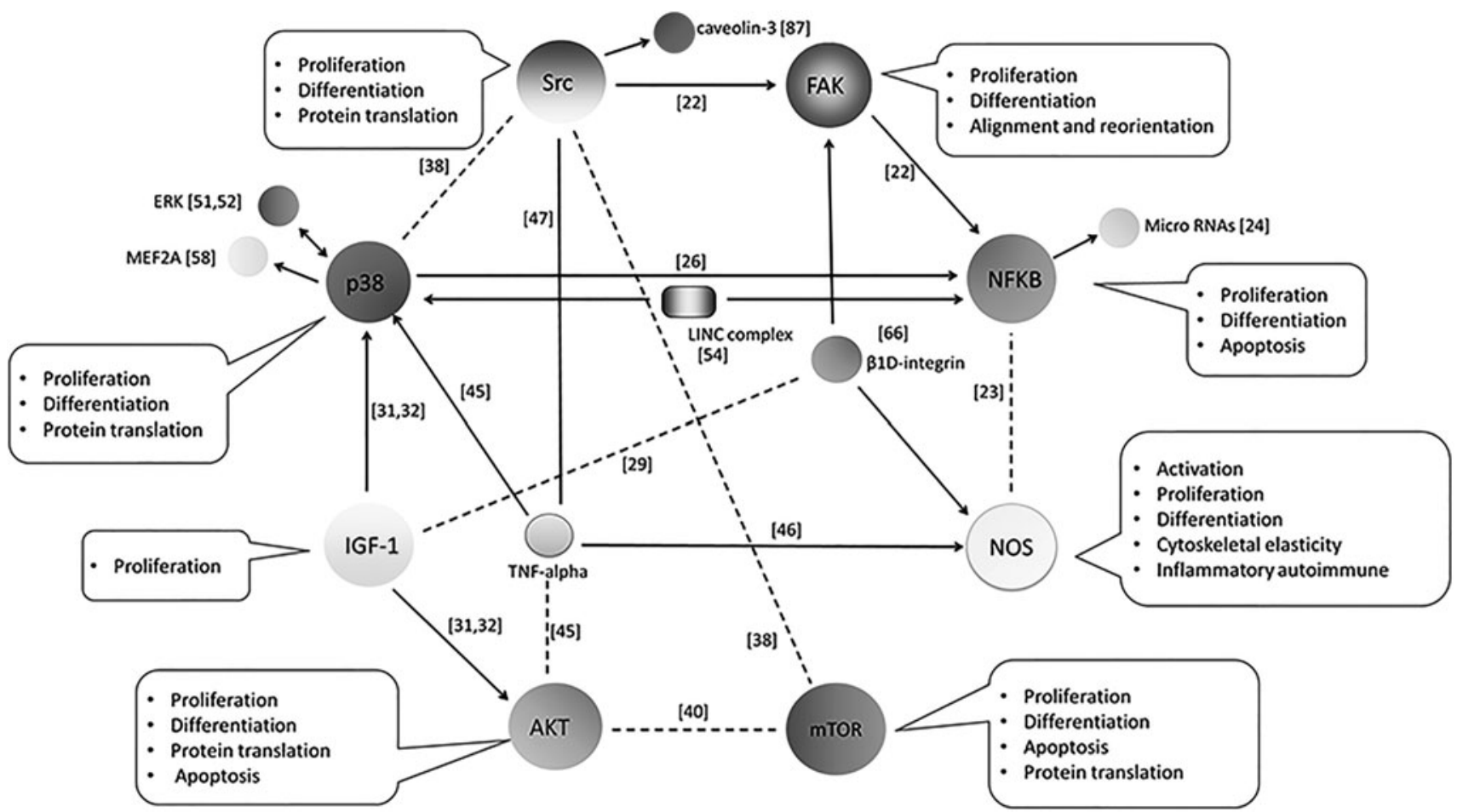

FIG. 3. Interconnections among the mechanosensitive pathways in skeletal myoblasts. In this review, several pathways were reported to be sensitive to various regimens of mechanical stretch, as displayed in different references. In addition, they were demonstrated to play distinct roles in mechanoresponses of myoblasts, which are summarized in the annotations beside each one of them. Notably, there were interconnections among these pathways in stretched myoblasts, with arrow line indicating direct regulation between two pathways, and dotted line suggesting possible indirect relation between two pathways. 
biomechanics, regeneration and reconstruction of muscle, medicine, kinesiology, etc.

\section{Author Disclosure Statement}

No competing financial interests exist.

\section{Funding Information}

This work was supported by the National Natural Science Foundation of China (no.11702154), the China Postdoctoral Science Foundation (no. 2018M642621), and the Qingdao Outstanding Health Professional Development Fund.

\section{References}

1. Narici M, M Franchi and C Maganaris. (2016). Muscle structural assembly and functional consequences. J Exp Biol 219 (Pt 2):276-284.

2. Goldspink G. (1999). Changes in muscle mass and phenotype and the expression of autocrine and systemic growth factors by muscle in response to stretch and overload. J Anat 194 (Pt 3):323-334.

3. Rassier DE. (2012). The mechanisms of the residual force enhancement after stretch of skeletal muscle: non-uniformity in half-sarcomeres and stiffness of titin. Proc Biol Sci 279: 2705-2713.

4. Sugi H and T Ohno. (2019). Physiological significance of the force-velocity relation in skeletal muscle and muscle fibers. Int J Mol Sci 20:3075.

5. Mauro A. (1961). Satellite cell of skeletal muscle fibers. J Biophys Biochem Cytol 9:493-495.

6. Yin H, F Price and MA Rudnicki. (2013). Satellite cells and the muscle stem cell niche. Physiol Rev 93:23-67.

7. Sheehan SM, R Tatsumi, CJ Temm-Grove and RE Allen. (2000). HGF is an autocrine growth factor for skeletal muscle satellite cells in vitro. Muscle Nerve 23:239-245.

8. Tatsumi R. (2010). Mechano-biology of skeletal muscle hypertrophy and regeneration: possible mechanism of stretch-induced activation of resident myogenic stem cells. Anim Sci J 81:11-20.

9. Tatsumi R, SM Sheehan, H Iwasaki, A Hattori and RE Allen. (2001). Mechanical stretch induces activation of skeletal muscle satellite cells in vitro. Exp Cell Res 267:107-114.

10. Tatsumi R, A Hattori, Y Ikeuchi, JE Anderson and RE Allen. (2002). Release of hepatocyte growth factor from mechanically stretched skeletal muscle satellite cells and role of pH and nitric oxide. Mol Biol Cell 13:2909-2918.

11. Tatsumi R and RE Allen. (2004). Active hepatocyte growth factor is present in skeletal muscle extracellular matrix. Muscle Nerve 30:654-658.

12. Tatsumi R, K Mitsuhashi, K Ashida, A Haruno, A Hattori, Y Ikeuchi, and RE Allen. (2004). Comparative analysis of mechanical stretch-induced activation activity of back and leg muscle satellite cells in vitro. Anim Sci J 75:341-351.

13. Yamada M, R Tatsumi, T Kikuiri, S Okamoto, S Nonoshita, W Mizunoya, Y Ikeuchi, H Shimokawa, K Sunagawa and RE Allen. (2006). Matrix metalloproteinases are involved in mechanical stretch-induced activation of skeletal muscle satellite cells. Muscle Nerve 34:313-319.

14. Yamada M, Y Sankoda, R Tatsumi, W Mizunoya, Y Ikeuchi, K Sunagawa and RE Allen. (2008). Matrix metalloproteinase2 mediates stretch-induced activation of skeletal muscle satellite cells in a nitric oxide-dependent manner. Int $\mathrm{J}$ Biochem Cell Biol 40:2183-2191.
15. Cha MC and PP Purslow. (2010). The activities of MMP-9 and total gelatinase respond differently to substrate coating and cyclic mechanical stretching in fibroblasts and myoblasts. Cell Biol Int 34:587-591.

16. Tatsumi R, A Hattori, RE Allen, $\mathrm{Y}$ Ikeuchi and $\mathrm{T}$ Ito. (2002). Mechanical stretch-induced activation of skeletal muscle satellite cells is dependent on nitric oxide production in vitro. Anim Sci J 73:235-239.

17. Hara M, K Tabata, T Suzuki, MK Do, W Mizunoya, M Nakamura, S Nishimura, S Tabata, Y Ikeuchi, et al. (2012). Calcium influx through a possible coupling of cation channels impacts skeletal muscle satellite cell activation in response to mechanical stretch. Am J Physiol Cell Physiol 302: C1741-C1750.

18. Tatsumi R, AL Wuollet, K Tabata, S Nishimura, S Tabata, W Mizunoya, Y Ikeuchi and RE Allen. (2009). A role for calcium-calmodulin in regulating nitric oxide production during skeletal muscle satellite cell activation. Am J Physiol Cell Physiol 296:C922-C929.

19. Formigli L, C Sassoli, R Squecco, F Bini, M Martinesi, F Chellini, G Luciani, F Sbrana, S Zecchi-Orlandini, F Francini and E Meacci. (2009). Regulation of transient receptor potential canonical channel 1 (TRPC1) by sphingosine 1phosphate in $\mathrm{C} 2 \mathrm{C} 12$ myoblasts and its relevance for a role of mechanotransduction in skeletal muscle differentiation. $\mathrm{J}$ Cell Sci 122 (Pt 9):1322-1333.

20. Yuan X, S Luo, Z Lin and Y Wu. (2006). Cyclic stretch translocates the alpha2-subunit of the $\mathrm{Na}$ pump to plasma membrane in skeletal muscle cells in vitro. Biochem Biophys Res Commun 348:750-757.

21. Chen R, L Feng, M Ruan, X Liu, S Adriouch and H Liao. (2013). Mechanical-stretch of C2C12 myoblasts inhibits expression of toll-like receptor 3 (TLR3) and of autoantigens associated with inflammatory myopathies. PLoS One 8:e79930.

22. Kumar A, R Murphy, P Robinson, L Wei and AM Boriek. (2004). Cyclic mechanical strain inhibits skeletal myogenesis through activation of focal adhesion kinase, Rac-1 GTPase and NF-kappaB transcription factor. FASEB J 18:1524-1535.

23. Soltow QA, VA Lira, JL Betters, JH Long, JE Sellman, EH Zeanah and DS Criswell. (2010). Nitric oxide regulates stretch-induced proliferation in $\mathrm{C} 2 \mathrm{C} 12$ myoblasts. J Muscle Res Cell Motil 31:215-225.

24. Hua W, M Zhang, Y Wang, L Yu, T Zhao, X Qiu and L Wang. (2016). Mechanical stretch regulates microRNA expression profile via NF-kappaB activation in $\mathrm{C} 2 \mathrm{C} 12$ myoblasts. Mol Med Rep 14:5084-5092.

25. Clark CB, NL McKnight and JA Frangos. (2004). Stretch activation of GTP-binding proteins in $\mathrm{C} 2 \mathrm{C} 12$ myoblasts. Exp Cell Res 292:265-273.

26. Ji G, D Liu, J Liu, H Gao, X Yuan and G Shen. (2010). p38 mitogen-activated protein kinase up-regulates NF-kappaB transcriptional activation through RelA phosphorylation during stretch-induced myogenesis. Biochem Biophys Res Commun 391:547-551.

27. Otis JS, TJ Burkholder and GK Pavlath. (2005). Stretchinduced myoblast proliferation is dependent on the COX2 pathway. Exp Cell Res 310:417-425.

28. Iwanuma O, S Abe, E Hiroki, S Kado, K Sakiyama, A Usami and Y Ide. (2008). Effects of mechanical stretching on caspase and IGF-1 expression during the proliferation process of myoblasts. Zoolog Sci 25:242-247.

29. Li Y, Z Zhao, J Song, Y Feng, Y Wang, X Li, Y Liu and P Yang. (2009). Cyclic force upregulates mechano-growth 
factor and elevates cell proliferation in 3D cultured skeletal myoblasts. Arch Biochem Biophys 490:171-176.

30. Cheema U, R Brown, V Mudera, SY Yang, G McGrouther and G Goldspink. (2005). Mechanical signals and IGF-I gene splicing in vitro in relation to development of skeletal muscle. J Cell Physiol 202:67-75.

31. Ma Y, S Fu, L Lu and X Wang. (2017). Role of androgen receptor on cyclic mechanical stretch-regulated proliferation of C2C12 myoblasts and its upstream signals: IGF-1mediated PI3K/Akt and MAPKs pathways. Mol Cell Endocrinol 450:83-93.

32. Fu S, L Yin, X Lin, J Lu and X Wang. (2018). Effects of cyclic mechanical stretch on the proliferation of L6 myoblasts and its mechanisms: PI3K/Akt and MAPK signal pathways regulated by IGF-1 receptor. Int J Mol Sci 19:pii:E1649.

33. Feng Y, J Wu, Z Cheng, J Zhang, J Lu and R Shi. (2019). Mechanical stretch enhances sex steroidogenesis in $\mathrm{C} 2 \mathrm{C} 12$ skeletal muscle cells. Steroids 150:108434.

34. Chen JF, Y Tao, J Li, Z Deng, Z Yan, X Xiao and DZ Wang. (2010). microRNA-1 and microRNA-206 regulate skeletal muscle satellite cell proliferation and differentiation by repressing Pax7. J Cell Biol 190:867-879.

35. Chen JF, EM Mandel, JM Thomson, Q Wu, TE Callis, SM Hammond, FL Conlon and DZ Wang. (2006). The role of microRNA-1 and microRNA-133 in skeletal muscle proliferation and differentiation. Nat Genet 38:228-233.

36. Cheng CS, Y El-Abd, K Bui, YE Hyun, RH Hughes, WE Kraus and GA Truskey. (2014). Conditions that promote primary human skeletal myoblast culture and muscle differentiation in vitro. Am J Physiol Cell Physiol 306:C385C395.

37. Kuang W, J Tan, Y Duan, J Duan, W Wang, F Jin, Z Jin, X Yuan and Y Liu. (2009). Cyclic stretch induced miR-146a upregulation delays $\mathrm{C} 2 \mathrm{C} 12$ myogenic differentiation through inhibition of Numb. Biochem Biophys Res Commun 378: 259-263.

38. Nakai N, F Kawano, Y Oke, S Nomura, T Ohira, R Fujita and Y Ohira. (2010). Mechanical stretch activates signaling events for protein translation initiation and elongation in C2C12 myoblasts. Mol Cells 30:513-518.

39. Wang M, Y Mou, Y Da, X Yuan, F Yan, W Lan and F Zhang. (2018). Effects of mammalian target of rapamycin on proliferation, apoptosis and differentiation of myoblasts undergoing mechanical stress. Am J Transl Res 10:41734182.

40. Miyazaki M and KA Esser. (2009). REDD2 is enriched in skeletal muscle and inhibits mTOR signaling in response to leucine and stretch. Am J Physiol Cell Physiol 296:C583C592.

41. Kim IS, YM Song, TH Cho, JY Kim, FE Weber and SJ Hwang. (2009). Synergistic action of static stretching and BMP-2 stimulation in the osteoblast differentiation of $\mathrm{C} 2 \mathrm{C} 12$ myoblasts. J Biomech 42:2721-2727.

42. Feng Y, XY Tian, P Sun, ZP Cheng and RF Shi. (2018). Simultaneous study of mechanical stretch-induced cell proliferation and apoptosis on $\mathrm{C} 2 \mathrm{C} 12$ myoblasts. Cells Tissues Organs 205:189-196.

43. Le Grand F and MA Rudnicki. (2007). Skeletal muscle satellite cells and adult myogenesis. Curr Opin Cell Biol 19:628-633.

44. Rauch C and PT Loughna. (2006). Cyclosporin-A inhibits stretch-induced changes in myosin heavy chain expression in $\mathrm{C} 2 \mathrm{C} 12$ skeletal muscle cells. Cell Biochem Funct 24: $55-61$.
45. Zhan M, B Jin, SE Chen, JM Reecy and YP Li. (2007) TACE release of TNF-alpha mediates mechanotransductioninduced activation of p38 MAPK and myogenesis. J Cell Sci 120 (Pt 4):692-701.

46. Chandran R, TJ Knobloch, M Anghelina and S Agarwal. (2007). Biomechanical signals upregulate myogenic gene induction in the presence or absence of inflammation. Am J Physiol Cell Physiol 293:C267-C276.

47. Niu A, Y Wen, H Liu, M Zhan, B Jin and YP Li. (2013). Src mediates the mechanical activation of myogenesis by activating TNFalpha-converting enzyme. J Cell Sci $126(\mathrm{Pt}$ 19):4349-4357.

48. Egusa H, M Kobayashi, T Matsumoto, J Sasaki, S Uraguchi and $\mathrm{H}$ Yatani. (2013). Application of cyclic strain for accelerated skeletal myogenic differentiation of mouse bone marrow-derived mesenchymal stromal cells with cell alignment. Tissue Eng Part A 19:770-782.

49. Andersen JI, CP Pennisi, T Fink and V Zachar. (2018). Focal adhesion kinase activation is necessary for stretchinduced alignment and enhanced differentiation of myogenic precursor cells. Tissue Eng Part A 24:631-640.

50. Abe S, S Rhee, O Iwanuma, E Hiroki, N Yanagisawa, K Sakiyama and Y Ide. (2009). Effect of mechanical stretching on expressions of muscle specific transcription factors MyoD, Myf-5, myogenin and MRF4 in proliferated myoblasts. Anat Histol Embryol 38:305-310.

51. Kook SH, YO Son, KC Choi, HJ Lee, WT Chung, IH Hwang and JC Lee. (2008). Cyclic mechanical stress suppresses myogenic differentiation of adult bovine satellite cells through activation of extracellular signal-regulated kinase. Mol Cell Biochem 309:133-141.

52. Kook SH, HJ Lee, WT Chung, IH Hwang, SA Lee, BS Kim and JC Lee. (2008). Cyclic mechanical stretch stimulates the proliferation of $\mathrm{C} 2 \mathrm{C} 12$ myoblasts and inhibits their differentiation via prolonged activation of p38 MAPK. Mol Cells 25:479-486.

53. Boonen KJ, ML Langelaan, RB Polak, DW van der Schaft, FP Baaijens and MJ Post. (2010). Effects of a combined mechanical stimulation protocol: value for skeletal muscle tissue engineering. J Biomech 43:1514-1521.

54. Brosig M, J Ferralli, L Gelman, M Chiquet and R ChiquetEhrismann. (2010). Interfering with the connection between the nucleus and the cytoskeleton affects nuclear rotation, mechanotransduction and myogenesis. Int $\mathrm{J}$ Biochem Cell Biol 42:1717-1728.

55. Akimotoab T, T Ushidabc, S Miyakib, T Tateishi and T Fukubayashi. (2001). Mechanical stretch is a down-regulatory signal for differentiation of $\mathrm{C} 2 \mathrm{C} 12$ myogenic cells. Mater Sci Eng C 17:75-78.

56. Dugan JM, SH Cartmell and JE Gough. (2014). Uniaxial cyclic strain of human adipose-derived mesenchymal stem cells and $\mathrm{C} 2 \mathrm{C} 12$ myoblasts in coculture. J Tissue Eng 5: 2041731414530138.

57. Molkentin JD, BL Black, JF Martin and EN Olson. (1995). Cooperative activation of muscle gene expression by MEF2 and myogenic bHLH proteins. Cell 83:1125-1136.

58. Rauch C and PT Loughna. (2005). Static stretch promotes MEF2A nuclear translocation and expression of neonatal myosin heavy chain in $\mathrm{C} 2 \mathrm{C} 12$ myocytes in a calcineurinand p38-dependent manner. Am J Physiol Cell Physiol 288: C593-C605.

59. Schiaffino S. (2018). Muscle fiber type diversity revealed by anti-myosin heavy chain antibodies. FEBS J 285:36883694. 
60. Kurokawa K, S Abe, K Sakiyama, T Takeda, Y Ide and K Ishigami. (2007). Effects of stretching stimulation with different rates on the expression of MyHC mRNA in mouse cultured myoblasts. Biomed Res 28:25-31.

61. Sakiyama K, S Abe, Y Tamatsu and Y Ide. (2005). Effects of stretching stress on the muscle contraction proteins of skeletal muscle myoblasts. Biomed Res 26:61-68.

62. Wang JH and BP Thampatty. (2006). An introductory review of cell mechanobiology. Biomech Model Mechanobiol 5:1-16.

63. Perdiguero E, V Ruiz-Bonilla, AL Serrano and P MunozCanoves. (2007). Genetic deficiency of p38alpha reveals its critical role in myoblast cell cycle exit: the p38alpha-JNK connection. Cell Cycle 6:1298-1303.

64. Keren A, Y Tamir and E Bengal. (2006). The p38 MAPK signaling pathway: a major regulator of skeletal muscle development. Mol Cell Endocrinol 252:224-230.

65. Wozniak MA and CS Chen. (2009). Mechanotransduction in development: a growing role for contractility. Nat Rev Mol Cell Biol 10:34-43.

66. Zhang SJ, GA Truskey and WE Kraus. (2007). Effect of cyclic stretch on beta1D-integrin expression and activation of FAK and RhoA. Am J Physiol Cell Physiol 292:C2057C2069.

67. Chang YJ, YJ Chen, CW Huang, SC Fan, BM Huang, WT Chang, YS Tsai, FC Su and CC Wu. (2016). Cyclic stretch facilitates myogenesis in $\mathrm{C} 2 \mathrm{C} 12$ myoblasts and rescues thiazolidinedione-inhibited myotube formation. Front Bioeng Biotechnol 4:27.

68. Moon du G, G Christ, JD Stitzel, A Atala and JJ Yoo. (2008). Cyclic mechanical preconditioning improves engineered muscle contraction. Tissue Eng Part A 14:473-482.

69. Pennisi CP, CG Olesen, M de Zee, J Rasmussen and V Zachar. (2011). Uniaxial cyclic strain drives assembly and differentiation of skeletal myocytes. Tissue Eng Part A 17: 2543-2550.

70. Bertrand AT, S Ziaei, C Ehret, H Duchemin, K Mamchaoui, A Bigot, M Mayer, S Quijano-Roy, I Desguerre, et al. (2014). Cellular microenvironments reveal defective mechanosensing responses and elevated YAP signaling in LMNA-mutated muscle precursors. J Cell Sci 127 (Pt 13): 2873-2884.

71. Zhang JS, WE Kraus and GA Truskey. (2004). Stretchinduced nitric oxide modulates mechanical properties of skeletal muscle cells. Am J Physiol Cell Physiol 287:C292C299.

72. Mitsui W, K Tamura, T Mizutani, H Haga and K Kawabata. (2009). Mechanical response of single myoblasts to various stretching patterns visualized by scanning probe microscopy. Arch Histol Cytol 72:227-234.

73. Herrmann H, H Bar, L Kreplak, SV Strelkov and U Aebi. (2007). Intermediate filaments: from cell architecture to nanomechanics. Nat Rev Mol Cell Biol 8:562-573.

74. Wang D, W Zheng, Y Xie, P Gong, F Zhao, B Yuan, W Ma, Y Cui, W Liu, et al. (2014). Tissue-specific mechanical and geometrical control of cell viability and actin cytoskeleton alignment. Sci Rep 4:6160.

75. Bonakdar N, J Luczak, L Lautscham, M Czonstke, TM Koch, A Mainka, T Jungbauer, WH Goldmann, R Schroder and B Fabry. (2012). Biomechanical characterization of a desminopathy in primary human myoblasts. Biochem Biophys Res Commun 419:703-707.

76. Bonakdar N, A Schilling, M Sporrer, P Lennert, A Mainka, L Winter, G Walko, G Wiche, B Fabry and WH Goldmann.
(2015). Determining the mechanical properties of plectin in mouse myoblasts and keratinocytes. Exp Cell Res 331:331337.

77. Charrier EE, A Asnacios, R Milloud, R De Mets, M Balland, F Delort, O Cardoso, P Vicart, S Batonnet-Pichon and S Henon. (2016). Desmin mutation in the C-terminal domain impairs traction force generation in myoblasts. Biophys J 110:470-480.

78. Diermeier S, J Iberl, K Vetter, M Haug, C Pollmann, B Reischl, A Buttgereit, S Schurmann, M Sporrer, et al. (2017). Early signs of architectural and biomechanical failure in isolated myofibers and immortalized myoblasts from desmin-mutant knock-in mice. Sci Rep 7:1391.

79. Liu J, J Liu, J Mao, X Yuan, Z Lin and Y Li. (2009). Caspase-3-mediated cyclic stretch-induced myoblast apoptosis via a Fas/FasL-independent signaling pathway during myogenesis. J Cell Biochem 107:834-844.

80. Liu J, Y Wang, X Yuan, Y Feng and H Liu. (2010). Cyclicstretch induces the apoptosis of myoblast by activation of caspase-3 protease in a magnitude-dependent manner. Int $\mathbf{J}$ Biochem Cell Biol 42:2004-2011.

81. Song J, Q Zhang, S Wang, F Yang, Z Chen, Q Dong, Q Ji, $X$ Yuan and D Ren. (2018). Cleavage of caspase-12 at Asp94, mediated by endoplasmic reticulum stress (ERS), contributes to stretch-induced apoptosis of myoblasts. J Cell Physiol 233:9473-9487.

82. Zhang Q, J Liu, S Chen, J Liu, L Liu, G Liu, F Wang, W Jiang, C Zhang, S Wang and X Yuan. (2016). Caspase-12 is involved in stretch-induced apoptosis mediated endoplasmic reticulum stress. Apoptosis 21:432-442.

83. Du Y, F Yang, D Lv, Q Zhang and X Yuan. (2019). MiR147 inhibits cyclic mechanical stretch-induced apoptosis in L6 myoblasts via ameliorating endoplasmic reticulum stress by targeting BRMS1. Cell Stress Chaperones [Epub ahead of print]; DOI: 10.1007/s12192-019-01037-4.

84. Wang F, ZL Wei, XR Sun, Q Zhang, CX Zhang, WX Jiang, X Yan, JN Liu and X Yuan. (2017). Apoptosis inducing factor is involved in stretch-induced apoptosis of myoblast via a caspase-9 independent pathway. J Cell Biochem 118: 829-838.

85. Tan J, W Kuang, Z Jin, F Jin, L Xu, Q Yu, L Kong, G Zeng, $X$ Yuan and Y Duan. (2009). Inhibition of NFkappaB by activated c-Jun NH2 terminal kinase 1 acts as a switch for C2C12 cell death under excessive stretch. Apoptosis 14: 764-770.

86. Song J, Y Wang, X Yuan, Q Ji, C Fan, H Zhao, W Hao and D Ren. (2019). Stretching magnitude-dependent inactivation of AKT by ROS led to enhanced p53 mitochondrial translocation and myoblast apoptosis. Mol Biol Cell 30: 1182-1197.

87. Gervasio OL, WD Phillips, L Cole and DG Allen. (2011). Caveolae respond to cell stretch and contribute to stretchinduced signaling. J Cell Sci 124 (Pt 21):3581-3590.

88. Leopold E and A Gefen. (2013). Changes in permeability of the plasma membrane of myoblasts to fluorescent dyes with different molecular masses under sustained uniaxial stretching. Med Eng Phys 35:601-607.

89. Slomka N and A Gefen. (2012). Relationship between strain levels and permeability of the plasma membrane in statically stretched myoblasts. Ann Biomed Eng 40:606618.

90. Leopold E and A Gefen. (2012). Stretching affects intracellular oxygen levels: three-dimensional multiphysics studies. J Biomech Eng 134:064501. 
91. Tosh D and JM Slack. (2002). How cells change their phenotype. Nat Rev Mol Cell Biol 3:187-194.

92. Iijima Y, T Nagai, M Mizukami, K Matsuura, T Ogura, H Wada, H Toko, H Akazawa, H Takano, H Nakaya and I Komuro. (2003). Beating is necessary for transdifferentiation of skeletal muscle-derived cells into cardiomyocytes. FASEB J 17:1361-1363.

93. Akimoto T, T Ushida, S Miyaki, H Akaogi, K Tsuchiya, Z Yan, RS Williams and T Tateishi. (2005). Mechanical stretch inhibits myoblast-to-adipocyte differentiation through Wnt signaling. Biochem Biophys Res Commun 329:381-385.

94. Marom A, Y Berkovitch, S Toume, MB Alvarez-Elizondo and D Weihs. (2019). Non-damaging stretching combined with sodium pyruvate supplement accelerate migration of fibroblasts and myoblasts during gap closure. Clin Biomech (Bristol, Avon) 62:96-103.

95. Ahmed WW, T Wolfram, AM Goldyn, K Bruellhoff, BA Rioja, M Moller, JP Spatz, TA Saif, J Groll and R Kemkemer. (2010). Myoblast morphology and organization on biochemically micro-patterned hydrogel coatings under cyclic mechanical strain. Biomaterials 31:250-258.

96. Leccia E, S Batonnet-Pichon, A Tarze, V Bailleux, J Doucet, M Pelloux, F Delort, V Pizon, P Vicart and F Briki. (2013). Cyclic stretch reveals a mechanical role for intermediate filaments in a desminopathic cell model. Phys Biol 10:016001.
97. Zeng W, S Jiang, X Kong, N El-Ali, AR Ball, Jr., CI Ma, N Hashimoto, K Yokomori and A Mortazavi. (2016). Singlenucleus RNA-seq of differentiating human myoblasts reveals the extent of fate heterogeneity. Nucleic Acids Res 44:e158.

98. Dell'Orso S, AH Juan, KD Ko, F Naz, J Perovanovic, G Gutierrez-Cruz, X Feng and V Sartorelli. (2019). Single cell analysis of adult mouse skeletal muscle stem cells in homeostatic and regenerative conditions. Development 146:pii:dev174177.

Address correspondence to: Dapeng Ren

Department of Stomatology Medical Center The Affiliated Hospital of Qingdao University Jiangsu Road No. 19

Qingdao, Shandong 266000

China

E-mail: rendapeng@qdu.edu.cn

Received for publication December 11, 2019

Accepted after revision January 16, 2020

Prepublished on Liebert Instant Online January 17, 2020 